International Journal of

Environmental Research and

Public Health

ISSN 1660-4601

www.mdpi.com/journal/ijerph

Review

\title{
Water-Related Parasitic Diseases in China
}

Shan Lv ${ }^{1,2}$, Li-Guang Tian ${ }^{1,2}$, Qin Liu ${ }^{1,2}$, Men-Bao Qian ${ }^{1,2}$, Qing Fu ${ }^{1,2}$, Peter Steinmann ${ }^{1,2,3}$, Jia-Xu Chen ${ }^{1,2}$, Guo-Jing Yang ${ }^{4,5}$, Kun Yang ${ }^{4}$ and Xiao-Nong Zhou ${ }^{1,2, *}$

1 National Institute of Parasitic Diseases, Chinese Center for Disease Control and Prevention, Key Laboratory of Parasite and Vector Biology, Ministry of Health, Shanghai 200025, China; E-Mails: lvshan000@126.com (S.L.); jztlg@126.com (L.-G.T.); liuqin0901 @ sohu.com (Q.L.); ahtlqmb-007@163.com (M.-B.Q.); fuqing1981@yahoo.com.cn (Q.F.); peter.steinmann@unibas.ch (P.S.); chenjiaxu@yahoo.com (J.-X.C.)

2 WHO Collaborating Centre for Malaria, Schistosomiasis and Filariasis, Shanghai 200025, China

3 Department of Epidemiology and Public Health, Swiss Tropical and Public Health Institute, University of Basel, Basel 4051, Switzerland

4 Jiangsu Institute of Parasitic Diseases, Wuxi 214064, China;

E-Mails: guojingyang@hotmail.com (G.-J.Y.); jipdyk@163.com (K.Y.)

5 School of Public Health and Primary Care, The Jockey Club Chinese University of Hong Kong, Shatin, Hong Kong

* Author to whom correspondence should be addressed; E-Mail: ipdzhouxn@sh163.net; Tel.: +86-21-6473-8058; Fax: +86-21-6433-2670.

Received: 5 April 2013; in revised form: 1 May 2013 / Accepted: 2 May 2013 /

Published: 17 May 2013

Abstract: Water-related parasitic diseases are directly dependent on water bodies for their spread or as a habitat for indispensable intermediate or final hosts. Along with socioeconomic development and improvement of sanitation, overall prevalence is declining in the China. However, the heterogeneity in economic development and the inequity of access to public services result in considerable burden due to parasitic diseases in certain areas and populations across the country. In this review, we demonstrated three aspects of ten major water-related parasitic diseases, i.e., the biology and pathogenicity, epidemiology and recent advances in research in China. General measures for diseases control and special control strategies are summarized. 
Keywords: parasitic disease; water; protozoa; helminths; epidemiology; China

\section{Introduction}

Water is a precondition for life, including that of all parasites and other organisms that infect humans. Indeed, many infectious diseases are water-related, i.e., they directly depend on water bodies for their spread and transmission or as a habitat for intermediate or final hosts [1].

Water-related parasites can be categorized into three groups according to their transmission route. The first group is associated with drinking water, which may be contaminated with cysts or oocysts, larvae, or eggs from various parasites. The second group is transmitted via penetration of the human skin during water contact. The parasites in this group may swim freely in water until they find a human host. The transmission of the third group of parasites depends on the consumption of uncooked freshwater products, e.g., plants, fish, snails or crustaceans. Obviously, the first two groups are closely related to water contact, while the key element of transmission of the third group is not water, but hosts and vectors living in the water.

This review focuses on the most important members of water-related parasitic diseases in China. Since their prevalence is influenced by the provision of clean water and sanitation, they are a priority of many rural development programmes [2]. We review will focus on the biology and pathogenicity, epidemiology and research advances of ten water-related parasitic diseases in China, and hope that this review will increase the recognition of these conditions in China and stimulate more studies in the area.

\section{Methods}

We reviewed the scientific literature on water-related parasitic diseases: amoebiasis, giardiasis, cryptosporidiosis, cyclosporiasis, blastocystosis, schistosomiasis, fascioliasis, fasciolopsiasis, clonorchiasis, and paragonimiasis. Considered publications were published from 1 January 1990 to 31 December 2011. The English language literature was obtained from ScienceDirect Onsite, SpringerLink and PubMed, while the Chinese language literature was obtained through CNKI (Chinese National Knowledge Infrastructure), Wanfang, and VIP.

For each disease, we firstly reviewed its biology and pathogenicity of that disease. Then, its epidemiology in China, particularly the two nationwide community-based sampling surveys on major human parasitic diseases which had been carried out during 1988-1992 (thereafter named "First National Survey") and 2001-2004 ("Second National Survey") respectively [3,4]. Thirdly, recent advances in research are introduced. We conclude with a discussion of control strategies for water-related diseases. 


\section{Results and Discussion}

\subsection{Amoebiasis}

\subsubsection{Parasite and Pathogenicity}

Pathogenic amoebiasis is caused by the protozoan parasite Entamoeba histolytica (Figure 1). Globally, the parasite causes an estimated 100,000 deaths per year and is one of the most important parasitic infections, ranking third in terms of public health relevance after malaria and schistosomiasis [5]. E. histolytica had been recognized as early as 1875 [6] and associated with variable morbidity. In 1993, the morphologically identical [7] but non-pathogenic E. dispar was described as a separate species [8], explaining the absence of morbidity in many amoebiasis cases. The failure of microscopic examinations to distinguish between the two species complicates the diagnosis in resource-constrained settings where specific ELISA or PCR tests are often not available.

Figure 1. Life cycle of Entamoeba histolytica (Available online: http://en.wikipedia.org/ wiki/File:Entamoeba_histolytica_life_cycle-en.svg).

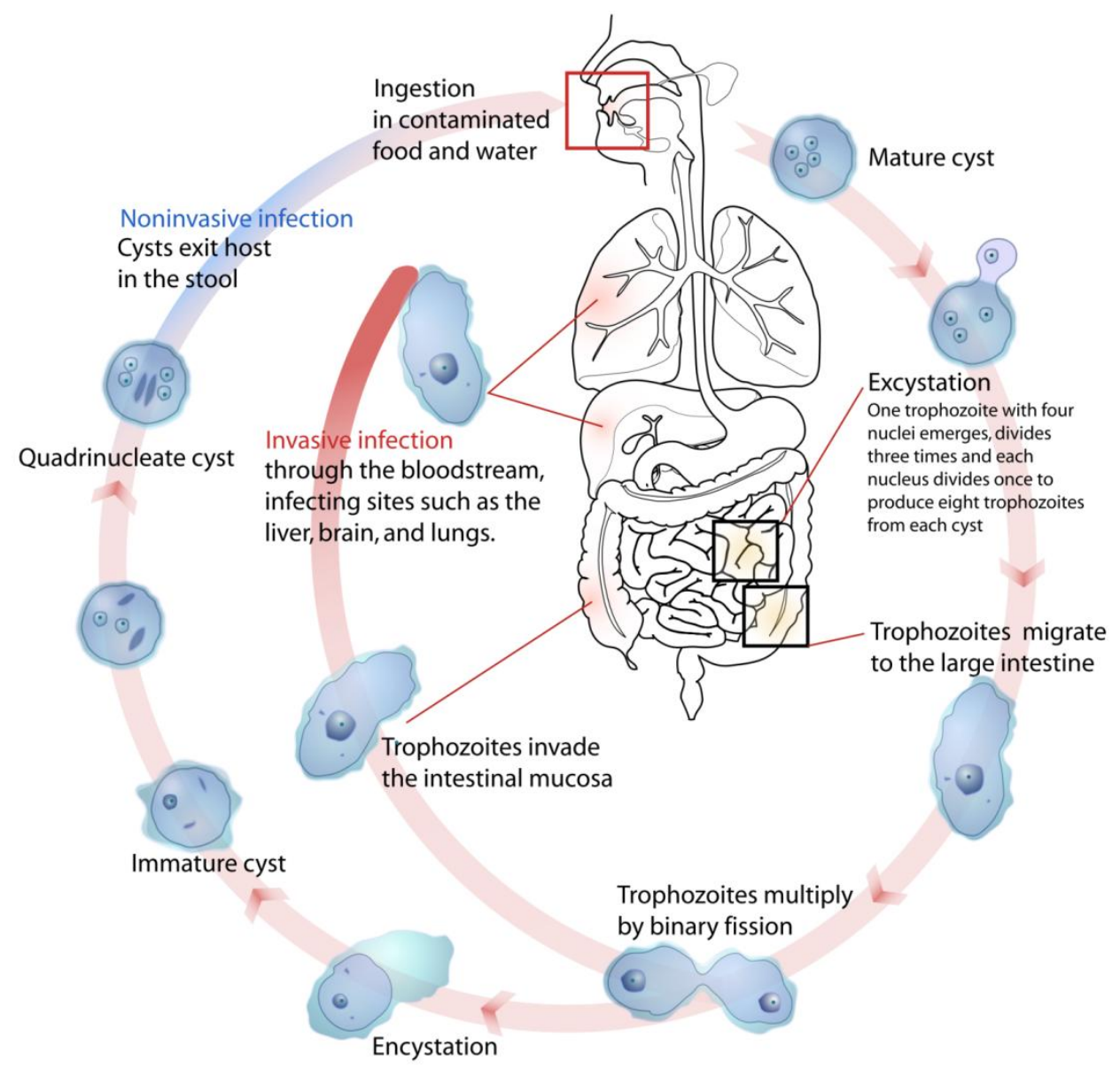

Infection is by ingestion of cysts (generally from fecally contaminated food or water). Excystation occurs in the ileum of the small intestine. Trophozoites multiply by binary fission in the large intestine. Most trophozoites remain in the lumen of the intestine. Cyst formation is triggered by dehydration of gut contents. Invasive forms of the disease lead to amoebic dysentery in which the trophozoites invade 
the intestinal wall, leading to the formation of amoebic ulcers. This results in severe diarrhea with blood and mucus in stools. If trophozoites penetrate the intestinal wall, serious health problems can occur, including liver abcesses (the most common manifestation), or spread to the lungs and brain, usually resulting in death, or other organs or tissues (e.g. pleura, pericardium, genitor-urinary system).

E. histolytica is a major cause of dysentery. Four major intestinal syndromes include asymptomatic colonization, acute amoebic colitis, fulminant colitis and amoeboma [9] (Table 1).

Table 1. Major syndromes of E. histolytica infection.

\begin{tabular}{l|ll}
\hline Syndrome & \multicolumn{2}{|l}{ Symptoms } \\
\hline Asymptomatic colonization & $\checkmark$ & No symptoms \\
(most common) & & \\
\hline Acute amoebic colitis & $\checkmark$ & Lower abdominal pain \\
& $\checkmark$ & Frequent bloody stools, over several weeks \\
& $\checkmark$ & Fever \\
\hline Fulminant colitis (occurs most often & $\checkmark$ & Diffuse abdominal pain \\
in children) & $\checkmark$ & Profuse bloody diarrhea \\
& $\checkmark$ & Fever \\
& $\checkmark$ & Liver abscess \\
& $\checkmark$ & Colonic perforation \\
\hline Amoeboma & $\checkmark$ & Asymptomatic lesion of colon wall \\
(approximately 1\% of patients) & $\checkmark$ & Tender mass accompanied by dysentery \\
\hline
\end{tabular}

\subsubsection{Epidemiology}

Amoebiasis is wide spread in rural China, as illustrated by the results of the first national survey [4] when more than 14,000 participants or $0.95 \%$ of the total were found to be infected, resulting in a the country-wide infection estimate of about 10 million individuals. E. histolytica has been reported from almost all provinces and the prevalence exceeded $1 \%$ in twelve provinces. Prevalence generally increased with age, while the steepest increase occurs from birth to the age of 14 years. The prevalence among farmers and shepherds was significantly higher compared to other groups and it has been suggested that different socio-economic factors synergistically impacted the prevalence. The results of the second national survey indicated that the prevalence of amoebiasis had generally declined. For example, the prevalence of E. histolytica had decreased from $1.50 \%$ to $0.14 \%$ in Zhejiang Province [10] and from $0.57 \%$ to $0.13 \%$ in Henan Province [11].

While the overall prevalence of amoebiasis in China is declining, some studies indicate that the proportion of diarrhea attributable to E. histolytica is increasing, particularly among paediatric outpatients [12,13]. Additionally, several outbreaks among migrant workers and children have been reported. In 2004, an epidemic occurred in a township of Dongguan city where about $54.4 \%$ of 263 inpatients with diarrhea were parasitologically confirmed as amoebiasis cases [14]. Of them, $84.6 \%$ were migrants and $79.7 \%$ were classified as paediatric patients. Poor living conditions of migrant workers and incomplete treatment resulting in chronic infections were described as the primary factors for the epidemic occurrence of amoebiasis in this area. Another outbreak in a township of Jiangshan city (Zhejiang Province) involved children from several kindergartens and primary schools [15]. 
Parasitic co-infections of HIV/AIDS patients are of particular concern [16]. In a cohort study involving participants from three provinces, the seroprevalence of E. histolytica among HIV-infected individuals was $12.1 \%$, four times the rate among non-HIV-infected individuals (3.1\%) [17].

\subsubsection{Recent Advances in Research}

Research pertaining to E. histolytica had been initiated relatively early in China when compared to other intestinal protozoa. In addition to numerous clinical reports of intestinal amoebiasis, extra-intestinal abscesses due to ectopic location of $E$. histolytica and amoebiasis due to other species have been highlighted recently. The significance of $E$. histolytica for animal health is also drawing attention $[18,19]$. Since traditional microscopic diagnosis of E. histolytica with or without iodine staining routinely fails to differentiate $E$. histolytica from $E$. dispar, enzyme-linked immunosorbent assays (ELISA) for E. histolytica in stool samples have been developed and evaluated [15,20,21]. Promising polymerase chain reaction (PCR) tests for detecting parasite DNA directly in liver abscess aspirates or serum sample have also been developed [21]. However, PCR is rarely used in China for the diagnosis of the parasite in stool samples, although good results have been reported from other countries [22].

\subsection{Giardiasis}

\subsubsection{Parasite and Pathogenicity}

Giardiasis is caused by Giardia intestinalis (also called G. lamblia or G.duodenalis) and is one of the most common causes of parasitic diarrhea. Today, giardiasis, along with cryptosporidiosis, continues to represent the major parasite-related public health concern of water utilities in developed nations [23]. G. intestinalis occurs worldwide and is a zoonotic parasite in certain areas while in others, the infection is believed to be limited to humans [24,25]. G. intestinalis exists in two forms, namely a trophozoite (the active form) and a cyst (the inactive form) (Figure 2).

The motile trophozoite has two nuclei, four pairs of flagella, and one or two curved median bodies of unknown function. Reproduction is by binary fission; no sexual process is known. The infective stage is an oval cyst, which is excreted in the faeces and ingested with contaminated food or water. The cyst contains four small nuclei, grouped at one end, and a confused jumble of flagella, median bodies etc. in the centre.

Diarrhea and associated symptoms may occur in various forms, depending on the stage of infection (Table 2). Symptoms pertaining to ectopic parasitism can be observed during the chronic stage; cholecystitis [26-28] and pancreatitis [29] have been associated with G. intestinalis infections, and the parasite has been isolated from ascites, pleural effusions and joint fluids [30-32]. The mechanisms involved in fatal giardiasis cases are not clear [32,33]. 
Figure 2. Life cycle of Giardia intestinalis (Available online: http://en.wikipedia.org/ wiki/File:Giardia_life_cycle_en.svg).

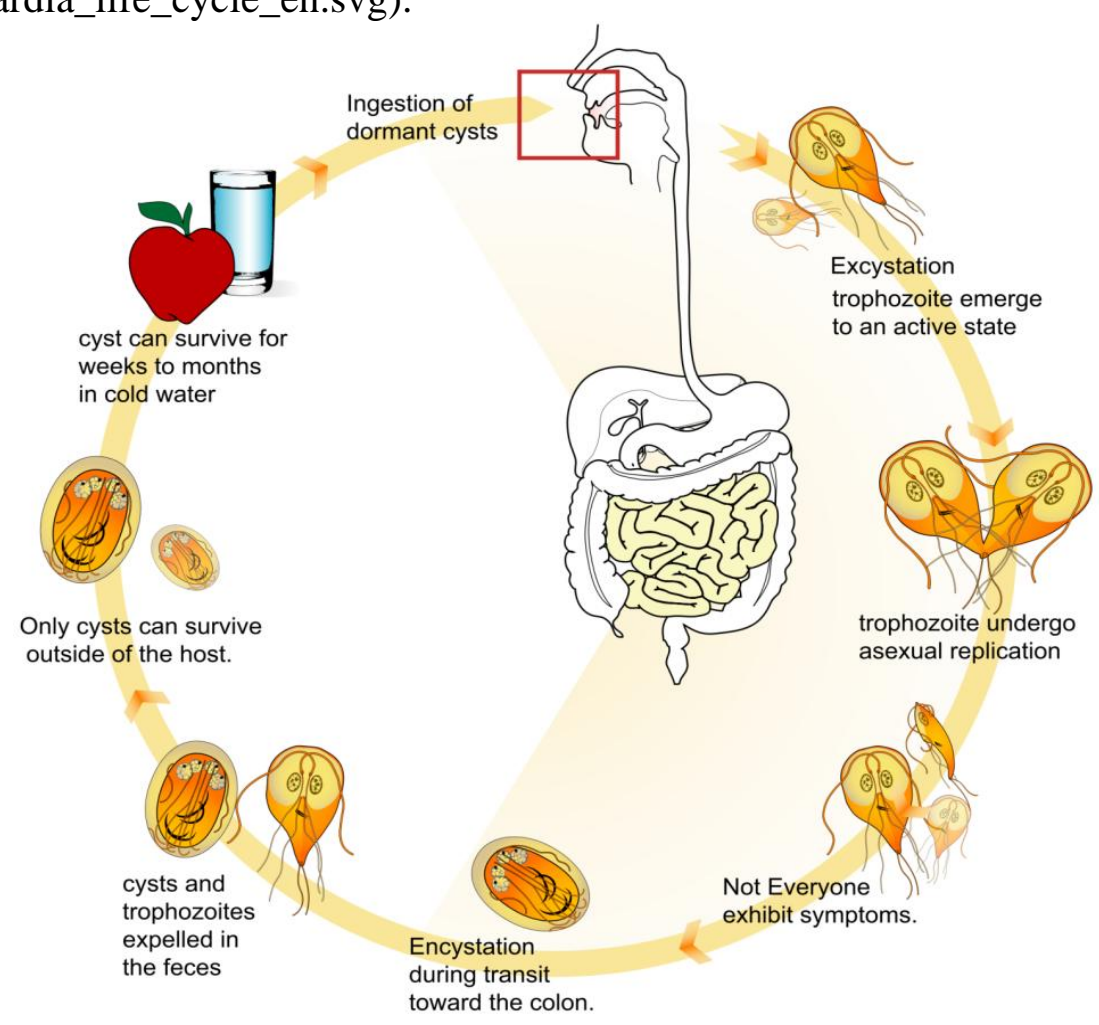

Table 2. Stages and symptoms of Giardiasis.

\begin{tabular}{l|ll}
\hline Stage & \multicolumn{2}{c}{ Symptoms } \\
\hline Prodromal & $\checkmark$ & Intestinal uneasiness \\
& $\checkmark$ & Nausea \\
& $\checkmark$ & Anorexia \\
\hline Acute (often lasts & $\checkmark$ & Explosive, watery, foul-smelling diarrhea \\
3-4 days, subsiding & $\checkmark$ & Low-grade fever \\
spontaneously) & $\checkmark$ & Chills \\
& $\checkmark$ & Abdominal bloating and cramping \\
& $\checkmark$ & Vomiting \\
& $\checkmark$ & Distention, associated with flatulence \\
\hline Chronic & $\checkmark$ & Blood and mucus in stools (rare) \\
& $\checkmark$ & Intermittent diarrhea \\
& $\checkmark$ & Abdominal bloating and cramping \\
& $\checkmark$ & Weight loss \\
& $\checkmark$ & Malnutrition \\
& $\checkmark$ & Growth retardation \\
\hline
\end{tabular}

\subsubsection{Epidemiology}

Giardiasis is the best-known intestinal protozoan infection in China where many field surveys have been conducted to reveal its epidemiology. Giardiasis occurs across the country and the overall prevalence has been estimated at $2.52 \%$ following the first national survey [4], translating into 28.5 million infections. The highest prevalences were found in Xinjiang Uyghur (9.26\%) and Tibet autonomous regions (8.22\%) and Henan Province (7.18\%). Regarding age, children under 
15 years were most affected with a peak prevalence of $4.67 \%$ in the age group 5-10 years (Figure 3). There was no significant difference between prevalences in males and females but family clustering was observed.

Figure 3. Change of infection rate of Giardia intestinalis prevalence by age and sex in China; the original data are obtained from Xu et al. [4].

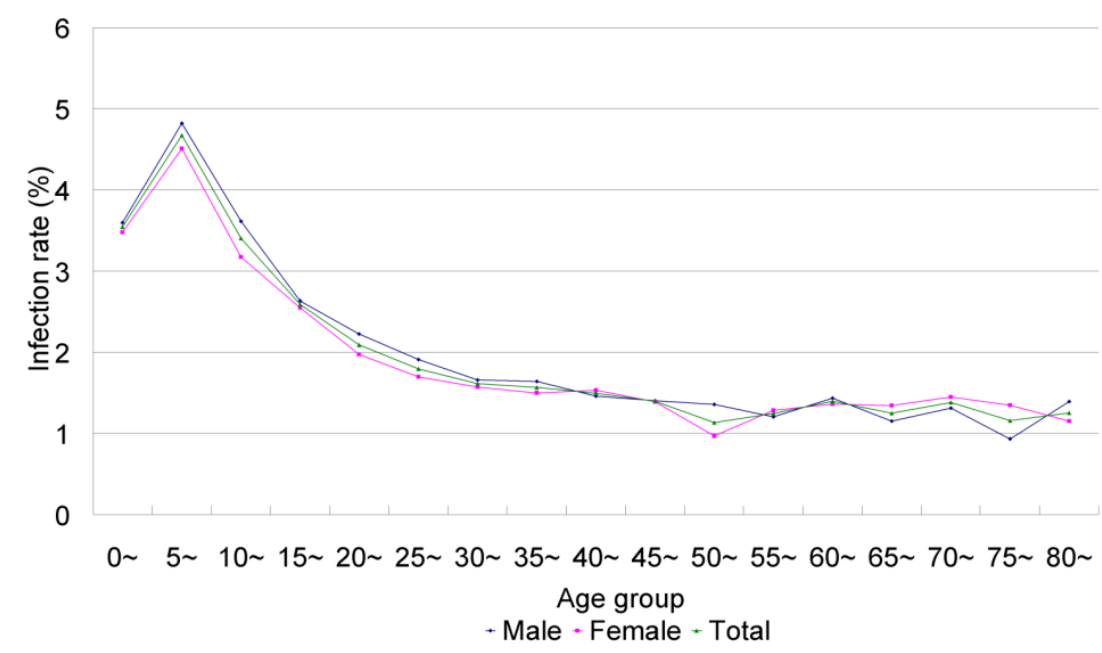

The prevalence of giardiasis in China is currently declining. According to the second national survey, the G. intestinalis prevalence had decreased significantly, e.g., from $7.18 \%$ in Henan Province and $3.85 \%$ in Zhejiang Province to $2.55 \%$ and $1.00 \%$, respectively [10,11]. Interestingly, the distribution of $G$. intestinalis does not always follow that of intestinal helminth infections, probably reflecting differences in the way of transmission with $G$. intestinalis more dependent on water and soil-transmitted helminths more dependent on faecal contamination of the solid environment. However, regional idiosyncrasies are also important. The prevalence of G. intestinalis was only $1.9 \%$ in a population in south Yunnan Province where the prevalence of each of the common soil-transmitted helminth species exceeded $85 \%$. Earlier observations had already noted that the prevalences of pathogenic intestinal protozoa were generally low in southeast Asia [34,35].

Although G. intestinalis infection is widespread in the general population, it is believed to be responsible for only a small fraction of all diarrhea cases. In a study conducted between 1996 and 2001 , only $0.32 \%$ of 3,116 diarrheal patients were found to be infected with $G$. intestinalis while the combined prevalence of all intestinal prototoa was $21.7 \%$. The majority of all intestinal protozoa were E. histolytica, infecting $17.65 \%$ of the samples [13]. Similarly, only $0.15 \%$ of 1,354 diarrheal patients were found to be infected with $G$. intestinalis in another study [36].

\subsubsection{Recent Advances in Research}

Besides basic epidemiological surveys, ectopic and severe infections have recently received more attention. Infections in the joints [32], tonsil [37], gall bladder [27,38,39] and thoracic cavity [30] have been described, helping to understand the true pathogenicity of $G$. intestinalis. Studies on viral infections of $G$. intestinalis will facilitate the study of mechanisms for invasion [40,41]. 
G. intestinalis and Cryptosporidium spp. are the protozoan parasites most frequently found in water bodies [42-44]. With increasing awareness of the importance of safe water supply, quality criteria for drinking water and standard examination methods have been proposed and implemented in China since 2007. The detection methods are based on the method 1623 "Cryptosporidium and Giardia in water by filtration/IMS/FA" initially published by the U.S. Environmental Protection Agency but certain procedures have been modified.

G. intestinalis has a zoonotic component and understanding its animal origins is crucial for the control of giardiasis. Based on electrophoretic evidence, there are at least seven valid assemblages $(\mathrm{A}-\mathrm{G})$ [45], of which humans can be infected by assemblages $\mathrm{A}$ and $\mathrm{B}$. The morphological identification of assemblages is difficult, rendering genetic biomarkers the major tool recently. The triose phosphate isomerase and ITS-5.8SrDNA genes are considered the best markers. Genetic analysis also showed that isolates with different host origins or from several geographic locations might share the same gene type. Therefore, host species and geographic isolation may play a subordinate role in the genetic diversity of $G$. intestinalis $[46,47]$.

Many protozoa have been found to be infected by a virus [48]. The Giardia lamblia virus (GLV) was first described as a specific double-stranded RNA virus in 1986 [49]. GLV isolated from humans in Beijing, China have been sequenced and appear to be identical to isolates from other places [41]. In another study performed in Changchun, the virus from G. canis was sequenced and found to be highly similar to GLV [50]. Based on GLV1515-2322, the coding part of the coat protein, an antiserum of GLV1518-2322 was prepared in order to detect GLV in G. intestinalis [51].

\subsection{Cryptosporidiosis}

\subsubsection{Parasite and Pathogenicity}

Cryptosporidiosis is a zoonosis caused by several Cryptosporidium species (Figure 4). The parasite was initially described from the gastric glands of laboratory mice and identified as a new species in 1912 [52].

The first cases of human cryptosporidiosis were independently reported from an immuno-compromised adult and a child in 1976 [53,54]. Cryptosporidium spp. are widely distributed in the environment. Many animals, including livestock and poultry, have been identified as sources of infection and the prevalence in animals is often considerably higher than that in humans [55-57].

Cryptosporidium spp. consists of an asexual stage and a sexual stage. After being ingested, the oocysts excyst in the small intestine. They release sporozoites that attach to the microvilli of the epithelial cells of the small intestine. From there they become trophozoites that reproduce asexually by multiple fission, a process known as schizogony. The trophozoites develop into Type I meronts that contain eight daughter cells. These daughter cells are Type 1 merozoites, which get released by the meronts. These merozoites can cause autoinfection by attaching to epithelial cells. They can aslo become Type II meronts, which contain 4 Type II merozoites. These merozoites get released and attach to the epithelial cells. From there they become either macrogamonts or microgamonts, the female and male sexual forms, respectively. This stage, when sexual forms arise, is called gametogony. Zygotes are formed by microgametes from the microgamont penetrating the macrogamonts. 
The zygotes develop into oocysts of two types. $20 \%$ of the oocysts have thin walls and so can reinfect the host by rupturing and releasing sporozoites that start the process over again. The thick-walled oocysts are excreted into the environment. The oocysts are mature and infective upon being excreted. They can survive in the environment for months.

Figure 4. Life cycle of Cryptosporidium spp. (Available online: http://en.wikipedia.org/ wiki/File:Cryptosporidiosis_01.png).

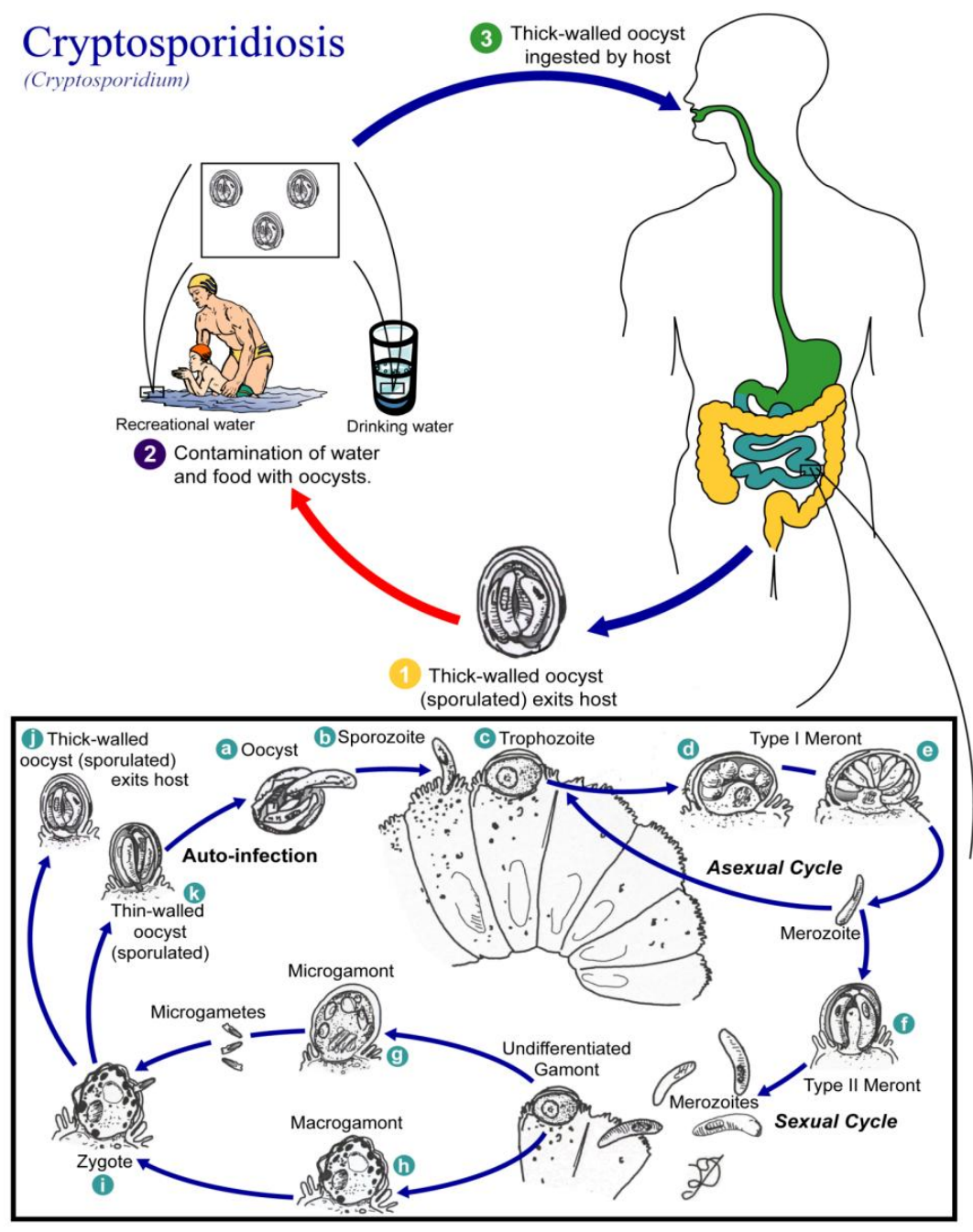

The incubation period in humans is about 5 to 28 days [52]. Infections with $C$. parvum have a wide range of manifestations, from asymptomatic to life-threatening disease (Table 3). Although C. parvum usually resides in the small intestine, symptomatic cryptosporidiosis has also been found to involve other digestive-tract organs, the lungs and possibly the conjunctiva [58]. 
Table 3. Effects of cryptosporidiosis related to prior physiological state of patient.

\begin{tabular}{l|ll}
\hline Patient Health & Effects \\
\hline Immunocompetent & $\checkmark$ & No effect \\
& $\checkmark$ & Cholera-like diarrhea; may contain mucus, but seldom blood and \\
& & leukocytes \\
& $\checkmark$ & Abdominal pain \\
& $\checkmark$ & Nausea and vomiting \\
& $\checkmark$ & Fever \\
& $\checkmark$ & Spontaneous recovery after short illness \\
\hline Immunocompromised & $\checkmark$ & Above symptoms, leading to dehydration and weight loss \\
& $\checkmark$ & Prolonged and potentially fatal illness \\
\hline
\end{tabular}

\subsubsection{Epidemiology}

Cryptosporidiosis is an increasing concern in the face of climbing HIV infection numbers in China. The first cryptosporidiosis case in China was reported in 1987 from Nanjing, Jiangsu Province [59]. At least 938 confirmed cases had been reported by 1998, more than $86.6 \%$ of them paediatric cases [4]. Tables 4 and 5 summarize the results of major C. parvum surveys among patients with diarrhea and the general population in China. An estimated $1.4 \%-10.4 \%$ of all diarrhea episodes can be attributed to Cryptosporidium (Table 4). Prevalences among the general population range from $0.79 \%$ to $6.59 \%$ (Table 5). An important reason for apparent variations in local prevalence are the epidemic nature of the disease and the use of different diagnostic techniques [60-62]. The prevalence varies between different places but no significant decrease following socioeconomic development can be discerned.

Children, particularly those under 5 years old, are more vulnerable to Cryptosporidium spp. infection than older age groups and the prevalence among pre-school age children is higher both among patients with diarrhea and in the general population. Generally, the prevalence is not significant different between males and females but prevalence is higher in rural and suburban areas compared to urban ones.

The pathogenicity of $C$. parvum is known to vary depending on the immune status. However, few investigations have specifically targeted immunosuppressed populations, such as patients with HIV/AIDS or cancer, in China. A recent survey showed that 4.25\% (9/212) of the screened AIDS patients were infected with $C$. parvum [63], with a higher prevalence among those who refused antiretroviral treatment $(21.21 \%$; 7/33). Cancer and chemo-radiotherapy often impair the immune system and thus promote Cryptosporidium infections. Two thirds of 108 patients with cancer were confirmed to be infected with Cryptosporidium in a recent study, and chemotherapy tended to be associated with higher prevalence than radiotherapy or combination therapy [64]. Several studies have also demonstrated a high prevalence among illegal drug addicts. In a study conducted in Dali, Yunnan Province, 16.8\% (84/500) of all injection drug users (IDUs) were found to be infected with this parasite upon stool examination while the prevalence was $6 \%$ among the general population [65]. In a similar study conducted in a drug rehabilitation center in Changsha, Hunan Province, the prevalence was $19.05 \%$ [66]. Of note, serological testing may result in higher prevalence estimates; in a study in Nanjing, Jiangsu Province a total of $69.9 \%$ of 588 IDUs were seropositive for specific antibodies as compared to $29.4 \%$ (113/384) among the general population, a significant difference [67]. 
Table 4. The prevalence of cryptosporidiosis in patients with diarrhea in China.

\begin{tabular}{|c|c|c|c|c|c|c|c|c|c|}
\hline \multirow{2}{*}{$\begin{array}{l}\text { Report } \\
\text { time }\end{array}$} & \multirow{2}{*}{$\begin{array}{c}\text { Location } \\
\text { (City, Province) }\end{array}$} & \multirow{2}{*}{$\begin{array}{c}\text { No. } \\
\text { exam }\end{array}$} & \multirow{2}{*}{$\begin{array}{c}\text { No. } \\
\text { infected }\end{array}$} & \multirow{2}{*}{$\begin{array}{l}\text { Infection } \\
\text { rate }\end{array}$} & \multicolumn{2}{|c|}{ Sex } & \multicolumn{2}{|c|}{ Age } & \multirow{2}{*}{ Reference } \\
\hline & & & & & male & female & Children & Adults & \\
\hline 1992 & Yuxi, Yunnan & 1,640 & 84 & 5.12 & - & - & $\begin{array}{l}7.99(52 / 651)(<5 \text { years }) \\
5.00(7 / 140)(6-10 \text { years }) \\
3.95(9 / 228)(11-20 \text { years })\end{array}$ & $\begin{array}{c}2.41(11 / 457) \\
(21-60 \text { years }) \\
4.81(5 / 104)(>60 \text { years })\end{array}$ & Fan et al, [68] \\
\hline 1993 & Kaifeng, Henan & 483 & 12 & 2.48 & - & - & $2.48(<4$ years $)$ & & Su et al. [69] \\
\hline 1998 & Harbin, Heilongjiang & 931 & 13 & 1.40 & - & - & $1.40(<4$ years $)$ & & Zhao et al. [70] \\
\hline 1999 & Wenzhou, Zhejiang & 1,060 & 60 & 5.66 & 5.18 & 6.38 & $6.13(59 / 962)(<15$ years $)$ & $1.02(1 / 98)(>15$ years $)$ & Xing et al. [71] \\
\hline 2000 & Hangzhou, Zhejiang & 548 & 57 & 10.40 & 10.31 & 10.60 & $10.40(<10$ years $)$ & & Lu et al. [72] \\
\hline 2001 & Chengdu, Sichuan & 406 & 12 & 2.96 & - & - & $2.96(<10$ years $)$ & & Zhang et al. [73] \\
\hline 2001 & Gansu Province & 1,840 & 41 & 2.23 & 2.01 & 2.50 & $\begin{array}{l}10.95(23 / 210)(<6 \text { years }) \\
1.82(7 / 385)(7-17 \text { years })\end{array}$ & $\begin{array}{l}0.88(11 / 1245) \\
(>18 \text { years })\end{array}$ & Chen et al. [74] \\
\hline 2002 & Urumqi, Xinjiang & 190 & 4 & 2.11 & 0.86 & 4.05 & $\begin{array}{l}1.56(1 / 64)(1-4 \text { years. }) \\
0.00(0 / 34)(5-11 \text { years })\end{array}$ & $0.00(0 / 12)(>60$ years $)$ & Luo et al. [75] \\
\hline 2002 & Yunnan Province & 378 & 20 & 5.29 & 5.11 & 5.45 & $7.09(9 / 127)(<15$ years $)$ & $\begin{array}{c}4.44(10 / 225) \\
(15-60 \text { years }) ; \\
3.85(1 / 26)(>60 \text { years })\end{array}$ & Zhang et al. [76] \\
\hline 2003 & Huainan, Anhui & 827 & 46 & 5.56 & 5.23 & 6.06 & $6.12(45 / 735)(<5$ years $)$ & $1.09(1 / 92)(>15$ years $)$ & Cai et al. [77] \\
\hline 2004 & Longhai, Fujian & 248 & 7 & 2.82 & 1.48 & 5.95 & $3.75(3 / 80)$ (<4 year $)$ & & $\mathrm{Xu}$ et al. [78] \\
\hline 2006 & $\begin{array}{c}\text { Qiqihar, } \\
\text { Heilongjiang }\end{array}$ & 330 & 11 & 3.33 & 2.69 & 4.17 & $5.61(6 / 107)(<15$ years $)$ & $\begin{array}{c}1.98(4 / 202) \\
(15-60 \text { years }) ; \\
4.76(1 / 21)(>60 \text { years })\end{array}$ & Niu et al. [79] \\
\hline 2006 & Shenyang, Liaoning & 237 & 6 & 2.53 & 2.00 & 3.40 & $\begin{array}{l}3.85(3 / 78) \text { (<1 year }) \\
2.17(2 / 92) \text { (<5 years); } \\
0.00(0 / 11) \text { (5-18 years); } \\
6.98(6 / 86) \text { (<18 years })\end{array}$ & $1.79(1 / 56)(18-72$ years $)$ & Li et al. [81] \\
\hline
\end{tabular}


Table 5. The prevalence of cryptosporidiosis in the general population in China.

\begin{tabular}{|c|c|c|c|c|c|c|c|c|c|}
\hline \multirow{2}{*}{$\begin{array}{l}\text { Report } \\
\text { time }\end{array}$} & \multirow{2}{*}{$\begin{array}{c}\text { Location } \\
\text { (City, Province) }\end{array}$} & \multirow{2}{*}{$\begin{array}{l}\text { No. } \\
\text { exam }\end{array}$} & \multirow{2}{*}{$\begin{array}{l}\text { No. } \\
\text { Infected }\end{array}$} & \multirow{2}{*}{$\begin{array}{l}\text { Infection } \\
\text { rate }\end{array}$} & \multicolumn{2}{|c|}{ Sex } & \multicolumn{2}{|c|}{ Age } & \multirow[b]{2}{*}{ Reference } \\
\hline & & & & & male & female & Children & Adult & \\
\hline 1991 & Nanjing, Jangsu & 2,018 & 16 & 0.79 & - & - & $0.79(<5$ years $)$ & & Shen et al. [82] \\
\hline 1991 & $\begin{array}{c}\text { Xuzhou and } \\
\text { Huaiyin, Jiangsu }\end{array}$ & 2,613 & 67 & 2.56 & - & - & $3.29(59 / 1794)$ & $0.98(8 / 819)$ & $\mathrm{Xu}$ et al. [83] \\
\hline 1992 & Qingdao, Shandong & 969 & 26 & 2.68 & 2.86 & 2.47 & $\begin{array}{l}\text { 2.68(preschool and primary } \\
\text { school) }\end{array}$ & & Gong et al. [84] \\
\hline 1992 & Hunan Province & 3,739 & 69 & 1.85 & 1.86 & 1.83 & $\begin{array}{l}2.52(57 / 2262)(<10 \text { years }) \\
1.99(10 / 503)(10-20 \text { years })\end{array}$ & $\begin{array}{l}0.21(2 / 974) \\
(>20 \text { years. })\end{array}$ & Lu et al. [85] \\
\hline 1992 & Yuxi, Yunnan & 2,853 & 42 & 1.47 & 1.32 & 1.60 & $\begin{array}{c}2.66(17 / 640)(<10 \text { years }) \\
1.47(10 / 680)(10-20 \text { years })\end{array}$ & $\begin{array}{c}0.92(12 / 1308) \\
(21-60 \text { years }) ; \\
1.33(3 / 225) \\
(>60 \text { years })\end{array}$ & Fan et al, [68] \\
\hline 1993 & Jiangsu Province & 5,089 & 89 & 1.75 & 1.91 & 1.54 & $\begin{array}{c}3.18(57 / 1793)(<4 \text { years }) \\
0.97(32 / 3296)(4-15 \text { years })\end{array}$ & & Chen et al. [86] \\
\hline 1995 & Xinjiang Province & 1,124 & 53 & 4.72 & 32 & 21 & $\begin{array}{l}10.59(34 / 321)(<5 \text { years }) \\
2.37(19 / 803)(6-10 \text { years })\end{array}$ & & Wang et al. [87] \\
\hline 2001 & Weifang, Shandong & 1,943 & 55 & 2.83 & 2.73 & 2.97 & $2.83(5-13$ years $)$ & & Cui et al. [88] \\
\hline 2004 & Anhui Province & 1,204 & 42 & 3.49 & 3.59 & 3.37 & 3.45(preschool children) & & Lu et al. [62] \\
\hline 2006 & Qiannan, Guizhou & 1,739 & 40 & 2.30 & 2.23 & 2.39 & $\begin{array}{l}\text { 8.76(12/137) (<2 years); } \\
3.76(7 / 186)(3-6 \text { years }) \\
1.99(4 / 201)(7-12 \text { years }) \\
2.77(8 / 289)(13-17 \text { years })\end{array}$ & $\begin{array}{l}0.97(9 / 926) \\
(>18 \text { years })\end{array}$ & Wang et al. [89] \\
\hline 2007 & Shiyan, Hubei & 941 & 62 & 6.59 & 6.88 & 6.26 & 6.59 (7-16 years.) & & Zhu et al. [90] \\
\hline 2007 & Shiyan, Hubei & 1,118 & 51 & 4.56 & 4.60 & 4.52 & 4.56 (3-6 years.) & & Zhu et al. [91] \\
\hline 2009 & Shiyan, Hubei & 2,549 & 119 & 4.67 & 4.82 & 4.51 & $5.99(110 / 1836)$ & $1.26(9 / 713)$ & Zhu et al. [92] \\
\hline 2009 & Nanjing, Jiangsu & 1,758 & 17 & 0.97 & 0.94 & 1.00 & 0.97 & & Du et al. [61] \\
\hline
\end{tabular}




\subsubsection{Recent Advances in Research}

The importance of Cryptosporidium in China is increasingly recognized. A high number of epidemiological investigations both in humans and animals have been conducted in the whole country, and prevalences in different population segments have been mapped. Co-infections of HIV and Cryptosporidium have attracted particular attention [93,94]. Cryptosporidium has been isolated from a range of animals and the taxonomy is still debated. Consequently, more and more studies are looking for suitable biomarkers and identification techniques to differentiate isolates [95]. Genetic variations have also been exploited for the development of source-tracing techniques [96]. Isolation techniques and diagnostic methods are also being developed in China. PCR-based techniques are the main methods currently applied to detect Cryptosporidium [97].

\subsection{Cyclosporiasis}

\subsubsection{Parasite and Pathogenicity}

Human cyclosporiasis is caused by Cyclospora cayetanensis and has been identified as an important cause of diarrhea worldwide. C. cayetanensis was classified into the subphylum Apicomplexa, family Eimeriidae in 1993 [98] and received its current name in 1994 [99]. Humans are the only known host of this parasite and are infected when ingesting oocysts in contaminated water, food or soil. The role of animals in the transmission of $C$. cayetanensis is uncertain but of increasing concern.

Infections with $C$. cayetanensis are often transient but chronic infections have also been described (Table 6). The shedding of oocysts need not concur with symptoms. Although symptoms and oocyst excretion typically subside within a few days to 1 or 2 weeks, some untreated persons excrete oocysts for 11 month after symptoms resolve [100,101]. Persistence of symptoms for several weeks longer than oocyst excretion has also been documented [102].

Table 6. Stages and Symptoms of Cyclosporiasis.

\begin{tabular}{l|ll}
\hline Stage & \multicolumn{2}{|l}{ Symptoms } \\
\hline Prodromal & $\checkmark$ & Flu-like symptoms \\
\hline Acute (often lasts a few & $\checkmark$ & Severe diarrhea \\
days to 1 or 2 weeks) & $\checkmark$ & Symptoms associated with gastroenteritis emerge with acute or gradual \\
& & onset of watery diarrhea, anorexia, fatigue, and weight loss \\
& $\checkmark$ & Loss of appetite, nausea, vomiting, abdominal bloating and cramps, body \\
& & aches, fever and chills, headache, and constipation \\
& $\checkmark$ & Ascending infection of biliary tract, in patients with AIDS \\
\hline Chronic & $\checkmark$ & Extended duration of symptoms above \\
& $\checkmark$ & Fatigue \\
& $\checkmark$ & Malaise \\
\hline
\end{tabular}

\subsubsection{Epidemiology}

Since 1995 when the first confirmed case of cyclosporiasis was reported in Fujian Province, China [103], C. cayetanensis has become an increasing concern in patients with diarrhea. The prevalence varies widely between places with higher prevalences usually found in tropical 
and humid areas at low elevation [104]. The prevalence in rural populations is higher than in urban populations [105,106].

Although C. cayetanensis is transmitted via similar routes as Cryptosporidium spp., their presence may be asymmetrical. For example, in a survey performed in Xishan County, Yunnan Province, $C$. parvum was diagnosed in $13 \%$ of all patients with diarrhea, while none of them was found to be infected with $C$. cayetanensis [104]. Many studies demonstrate paediatric patients with diarrhea are more likely to be infected with Cryptosporidium spp., whereas a recent study showed that the prevalence of cyclosporiasis in the group above 60 years was significantly higher than in younger age groups [106]. The proportion of $C$. cayetanensis infections may be particularly elevated in chronic diarrhea patients. For example, a study showed that $8.2 \%$ of all patients with chronic diarrhea were infected with $C$. cayetanensis while only $2.5 \%$ of the patients with acute diarrhea were infected with this parasite [106]. C. cayetanensis infections also impact the immune status. A study revealed that cyclosporiasis patients had a decreased level of $\mathrm{CD}^{+}$and $\mathrm{CD}^{+}$, while $\mathrm{CD} 8^{+}$was normal [107].

\subsubsection{Recent Advances in Research}

Although the prevalence of cyclosporiasis among diarrheal patients can be considerable as documented in several provinces of China, few epidemiological surveys have been implemented and many techniques applied to cryptosporiasis have not been introduced to cyclosporiasis research. Consequently, one challenge in epidemiological surveys is the lack of sensitive techniques to differentiate C. cayetanensis from other intestinal protozoa. Indeed, misdiagnosis is common [108].

Humans currently are the only known host of $C$. cayetanensis. The lack of an animal model prevents studying this parasite [109]. To overcome this limitation, Ge and colleagues established a rat model for $C$. cayetanensis. They first suppressed the immune system of rats using hydrocortisone or cyclophosphamide and then infected them with $C$. cayetanensis. The number of oocysts in stool gradually increased and reached a peak 5-7 days after infection [110].

The susceptibility to $C$. cayetanensis infection is thought to be related to the status of the immune system. A series of relevant studies was performed in order to reveal the relationship between the likelihood of an infection and different immune status parameters [107,111,112]. It was found that among the infected, the titer of membrane interleukin- 2 receptor, $\mathrm{CD}^{+}$and $\mathrm{CD}^{+}{ }^{+}$was significantly decreased relative to non-infected individuals, while that of soluble interleukin-2 receptor as well as specific IgG and IgM were significantly elevated.

\subsection{Blastocystosis}

\subsubsection{Parasite and Pathogenicity}

Blastocystis hominis is one of the most frequently diagnosed protozoan parasites in human faecal samples. It is found in both symptomatic and healthy individuals and therefore, its pathogenic potential is still debated [113]. Additionally, many aspects of this organism including its taxonomy, life cycle and mode of transmission continue to be controversial despite this parasite being first discovered in human faeces as early as 1912 [114]. The morphologic diversity of the organism and the low sensitivity of the generally used wet-mount detection technique add further difficulties to its study [113]. 
Most people carrying $B$. hominis infections are asymptomatic while some show gastrointestinal symptoms including diarrhea, abdominal discomfort, abdominal pain or abdominal cramping and vomiting. Acute infections may cause watery diarrhea. In addition, fatigue, loss of appetite, bloating, and other non-specific gastrointestinal symptoms have been associated with $B$. hominis infections.

\subsubsection{Epidemiology}

B. hominis is endemic across the World, with a focus in tropical and subtropical regions. The first national survey showed that the overall prevalence $B$. hominis in China was $1.3 \%$ [4]. The parasite was found in 22 provinces; the highest provincial-level prevalence of $B$. hominis was $8.0 \%$ in Sichuan Province [4]. However, these figures probably underestimate the real situation. A recent study on B. hominis not only revealed that the prevalence can be as high as $32.6 \%$ in a subtropical rural area located in Yunnan Province and $1.9 \%$ in the urban population in Shanghai, but also showed that sensitive culture methods detect over 1.5 times more cases than a more conventional ether concentration approach $[35,115]$.

The B. hominis prevalence in patients with diarrhea is considerable albeit it is often not clear whether their condition is due to the infection with this parasite. A recent study performed in Guangxi Zhuang Autonomous Region collected stool samples from 1,354 diarrheal outpatients among whom $18.5 \%$ were infected with B. hominis [36]. The proportion can be even higher in patients with chronic diarrhea [116]. Co-infection with other parasites is common; in the study from Guangxi mentioned above, $31.9 \%$ of all patients with B. hominis were simultaneously infected with other parasites [36]. The most common accompanying parasite, Clonorchis sinensis, accounted for $71.3 \%$ of all co-infections. Another survey showed an even higher co-prevalence of 51.1\% among patients with B. hominis and one third of these co-infections were attributable to G. intestinalis [116]. Unlike cryptosporidiosis and cyclosporiasis, several studies found that middle-aged individuals are most susceptible to B. hominis [36,117].

Diarrhea outbreaks have rarely been attributed to B. hominis. A big diarrhea outbreak presumably due to this parasite occurred in a township of Chongyi County, Jiangxi Province in 1996 [118] where 1,122 diarrheal patients were reported within eight days (Figure 5). Contaminated drinking water has been identified as the most likely source of infection (Table 7).

Figure 5. An outbreak of Blastocystis hominis in Hengshui Township, China. The original data are obtained from $\mathrm{Wu}$ et al. [118].

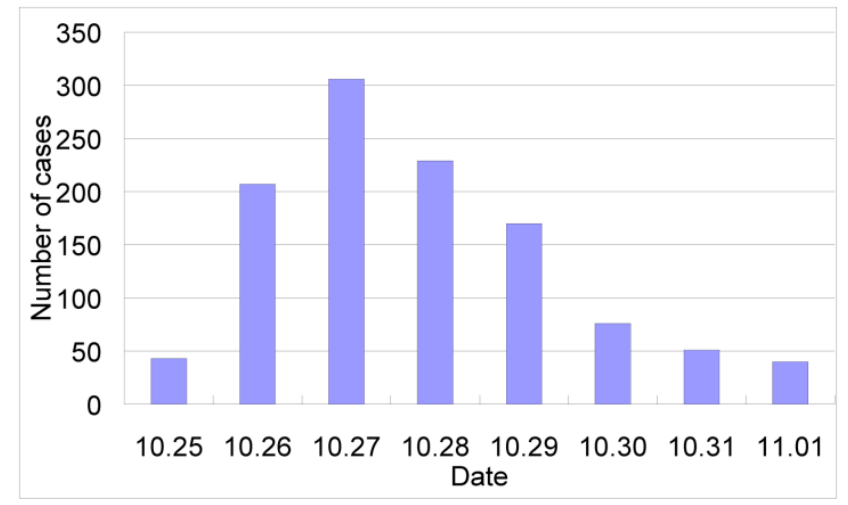


Table 7. An outbreak of Blastocystis hominis in Hengshui Township, China.

\begin{tabular}{ccccc}
\hline School & $\begin{array}{c}\text { No. } \\
\text { students }\end{array}$ & $\begin{array}{c}\text { Source of } \\
\text { drinking water }\end{array}$ & $\begin{array}{c}\text { No. } \\
\text { cases }\end{array}$ & $\begin{array}{c}\text { Infection } \\
\text { rate (\%) }\end{array}$ \\
\hline Chongyi middle school & 1,524 & running water & 106 & 6.96 \\
Technical school & 1,074 & spring water & 5 & 0.47 \\
Hengshui middle school & 608 & well water & 2 & 0.33 \\
Chengguan primary school & 2,326 & running water & 264 & 11.35 \\
Chengguan kindergarten & 411 & running water & 117 & 28.47 \\
Woman united kindergarten & 324 & running water & 62 & 19.14 \\
\hline Total & 6,267 & & 556 & 8.87 \\
\hline
\end{tabular}

\subsubsection{Recent Advances in Research}

Recent studies relevant to $B$. hominis have focused on diagnostics, the relationship between the parasite and diarrhea, and molecular epidemiology. Traditional methods to detect this protozoan parasite from stool sample include direct smears and staining with different dyes. A study compared three culture methods with different media, i.e., RPMI1640, 199 and LES, and found RPMI1640 to be the most sensitive of them. In this medium, B. hominis can survive for a longer time and the final quantity of cells was the largest [119]. Recently, in vitro broth culture was confirmed to effectively improve the detection rate of $B$. hominis in human stool [120].

The pathogenicity of $B$. hominis has been confirmed in mice [121]. A case control study revealed that $B$. hominis infections in humans cause inflammation in the left colon and rectum [122]. The degree of impairment was positively correlated with the infection intensity. The titers of IL28, IL218 and GM2CSF in the intestinal mucous membrane were significantly elevated compared to healthy individuals, and again positively correlated with infection intensity. It has thus been concluded that B. hominis infections induce and mediate immune responses of epithelial cells that eventually result in inflammation.

A total of five genotypes including one which was previously unknown were found in a molecular epidemiological study in China [115]. The consumption of raw water plants was positively associated with subtype 1 , and drinking unboiled water was positively associated with subtype 3 . Genotype proportions varied between counties and mixed infections were common. It has been concluded that human infections with different genotypes might result from infections over different transmission routes and sources of infection [123].

\subsection{Schistosomiasis}

\subsubsection{Parasite and Pathogenicity}

Schistosoma japonicum, the Asian or oriental schistosome, is endemic in China, the Phillipines and a small area of Indonesia. The morbidity due to schistosomiasis can mainly be attributed to the eggs trapped or dispersed on their way from the blood vessel-dwelling flukes to the intestine and the resulting immune reactions. The flukes themselves cause little disturbance [124]. Infection takes place in water bodies where the cercariae - larvae that emerge from intermediate host snails_-actively target 
suitable end hosts and penetrate their skin. Schistosomiasis japonica has unique characteristics compared to the four other specise of human schistosomes, namely S. masoni, S. hamatobium, S. intercalatum and S. mekongi. Firstly, over 40 animal species, including cattle, pigs, dogs, cats and goats can serve as natural definitive hosts, rendering it a zoonotic rather than anthroponotic parasite. Secondly, the intermediate host snail Oncomelania hupensis is amphibious rather than aquatic. Third, the disease is characterized by more severe morbidity than that due to other species since the number of eggs produced per female worm is higher. Symptoms can become severe due to high infection intensities or extended exposure due to untreated illness (Table 8).

Table 8. Stages and Symptoms of Schistosomiasis japonica.

\begin{tabular}{l|ll}
\hline Stages & Symptoms \\
\hline Acute (exposure to high & $\checkmark$ & High fever \\
numbers of cercaria) & $\checkmark$ & Hepatomegaly \\
\hline & $\checkmark$ & Liver fibrosis \\
& $\checkmark$ & Liver cirrhosis \\
Chronic (untreated acute & $\checkmark$ & Liver portal hypertension \\
infection) & $\checkmark$ & Splenomegaly \\
& $\checkmark$ & Ascites \\
\hline Infection outside intestines, & $\checkmark$ & Morbidity due to immune reactions to eggs trapped or dispersed in \\
liver and spleen & & lungs, nervous system, and other organs \\
\hline
\end{tabular}

\subsubsection{Epidemiology}

Schistosomiasis japonica is one of the most important parasitic diseases in China and its epidemiology has been extensively studied and reviewed [125]. When the national control programme was launched in the 1950s, the disease was common in many areas south of the Yangtze River, including Anhui, Fujian, Guangdong, Hubei, Hunan, Jiangsu, Jiangxi, Sichuan, Yunnan and Zhejiang Provinces, the Guangxi Zhuang Autonomous Region and Shanghai Municipality. The lowest-lying endemic area was recorded at sea level and the highest one in Yunnan Province at 3,000 m. The most severely affected areas were located along the Yangtze River, in the areas of the great lakes (i.e., Dongting and Poyang lake) and surrounding areas [126]. Today, the parasite has been eliminated from Fujian, Guangdong, Guangxi, Zhejinag and Shanghai [125]. Substantial progress in controlling schistosomiasis has also been achieved in most of the remaining endemic areas and the total number of infected people has been reduced by over $90 \%$ since 1950 [127,128]. A nationwide sampling survey conducted in 2004 provided a detailed picture of the contemporary epidemiological situation and put the number of infections at 720,000 [129]. In 2008, the number of infections was estimated at about 412,000 [130].

The schistosome-endemic areas of China have been stratified into three types, based on ecosystem characteristics, namely the plain and water-network region, marshland and lake region, and hilly and mountainous region. The parasite has been eliminated from the formerly most heavily endemic plain and water-network region and has largely been brought under control in the hilly and mountainous regions. However, control in the marshland and lake regions proved difficult and the disease remains prone to resurgence [130]. 


\subsubsection{Recent Advances in Research}

The successes with schistosomiasis control in China have been attributed to strong government support and sustainable yet adaptable policies [131]. Since the prevalence in human has declined significantly, animals, most notably livestock, have become the major source of infection in most areas. A recent study showed that a comprehensive control strategy focusing on interventions to reduce the transmission from cattle and humans to snails was highly effective [132]. This strategy has now been implemented in more than 90 counties across five endemic provinces and it has been suggested that the official target of reducing the prevalence in all endemic counties to less than $1 \%$ by 2015 could be achieved [132].

Disability adjusted life years (DALYs) have been widely used to measure disease burden and direct the allocation of health resources [133]. However, recent studies and meta-analyses challenge the current estimates of schistosomiasis-related diseases burden [134]. A recent study performed in China found that the overall disability weight of chronic schistosomiasis japonica was 0.191 , with age-specific weights ranging from 0.095 to 0.246 [135]. These numbers are significantly higher than those used to evaluate global disease burden in 2004, namely 0.005 among those aged < 15 years and 0.006 among those aged $>15$ years [136].

The transmission of $S$. japonicum is subject to environmental conditions and changes therein, including climate change [137-139]. It has been predicted that the potential endemic area will markedly expand northward and include an additional $783,883 \mathrm{~km}^{2}$ by 2050 , accounting for $8.1 \%$ of the surface area of China [137]. Based on this prediction, efforts for adaptation and surveillance are ongoing [140].

The genomes of $S$. japonicum has been sequenced and published [141,142]. Transcriptomics and proteomics studies are in progress [143]. Vaccine development, drug discovery and improvements of diagnostic techniques are further research topics [144-146]. The mitochondrial genome of $O$. hupensis has also been studied, and genetic markers have been used to analyze the spatial distribution of the snail in China [147,148].

\subsection{Fascioliasis}

\subsubsection{Parasites and Pathogenicity}

Human fascioliasis is caused by $F$. hepatica and $F$. gigantica. Both species are endemic in China. The life cycle of these two species are essentially similar [149]. They use herbivorous mammals as definitive host and freshwater snails (Lymnaeidae) as intermediate hosts [150]. The adult worms parasitize dwell in the biliary system of definitive hosts (cattle, sheep, etc.). The eggs are released to the intestine and exit the host body with faeces. Hatched miracidia invade freshwater snail host and develop to cercaria. The latter emerge from snails and stick to aquatic plants and finally become metacercariae. Humans and mammals acquire infection by ingesting aquatic plants contaminated with metacercariae [150].

Larval migration in the liver induces inflammation and hepatic dysfunction, which is the main base for acute symptoms (Table 9). Intermittent high fever and hepatalgia are the major symptoms at the acute stage [151-154]. The eosinophil count normally increases. The discovery of eggs in faeces is 
rare at this stage. Chronic symptoms coincide with the persistence of Fasciola spp. worms in the bile ducts. Many cases of chronic fascioliasis are asymptomatic. Jaundice appears when biliary obstruction occurs. Ectopic parasitism in cutaneous tissue, lung and other organs has also been reported [155,156]. Severe infections can lead to fatal outcome [154,157].

Table 9. Stages and symptoms of Fascioliasis.

\begin{tabular}{l|ll}
\hline Stages & Symptoms \\
\hline & $\checkmark$ & Fever (almost all patients) \\
& $\checkmark$ & Hepatalgia (almost all patients) \\
Acute (last a few & $\checkmark$ & Hepatomegaly \\
months) & $\checkmark$ & Tenderness in epigastrium \\
& $\checkmark$ & Percussion pain in liver \\
& $\checkmark$ & Weigh loss \\
& $\checkmark$ & Anaemia \\
\hline \multirow{2}{*}{ Chronic } & $\checkmark$ & Jaundice \\
\hline \multirow{2}{*}{ Infection outside biliary } & $\checkmark$ & Hepatalgia \\
system & $\checkmark$ & Cutaneous mass \\
& $\checkmark$ & Symptoms related to involvement of lungs, peritoneum, brain, thyroid, \\
\hline
\end{tabular}

\subsubsection{Epidemiology}

Fascioliasis is a common parasitic disease in domestic animals in China and hence causes huge economic losses. Human fascioliasis has rarely been reported in the past decades. $F$. hepatica is considered the major cause of animal and human fascioliasis in China. Before 1990 a total of 45 human cases had been reported, including one case of fascioliasis gigantica [157]. The first national survey discovered 148 fascioliasis hepatica and nine fascioliasis gigantica cases among 1.5 million participants [4]. The cases were distributed in 18 out of 31 provinces in China [4], which indicated a large number of people were at risk of fascioliasis. Compared to fascioliasis hepatica, all nine human cases caused by F. gigantica were localized in Hainan Island, the southernmost province of China. However, recent phylogenetic analysis of isolates from different areas in the country showed three distinct clades, i.e., F. hepatica, F. gigantica, and the "intermediate" type [158]. F. gigantica is also distributed in southwest part of China, including Guangxi and Guizhou Provinces [159,160]. Therefore, the cases due to $F$. gigantica probably occurred in southwest China.

Although the second national survey on major parasitic diseases did not include fascioliasis [3], sporadic reports of human cases impliy a low prevalence in the past two decades. A total of 49 human cases, excluding the cases identified in the first national survey, were recorded. Notably, 40 cases were reported in the last ten years, which indicates a growing prevalence of fascioliasis in China.

\subsubsection{Recent Advances in Research}

Fascioliasis is an important disease in livestock and hence veterinary studies are predominant in literature. In contrast, only few human case reports have been published in literature in recent years. Triclabendazole is the most efficacious drug for treating human fascioliasis. However, the drug is only 
registered in a few countries, and not in China [161]. The majority of all patients in China are treated with praziquantel. The distribution of triclabendazole should be promoted.

In the last ten years, molecular identification of Fasciola species was performed. Mitochondrial gene ( $\operatorname{cox} 1$ and nad1) and internal transcribed spacers (ITS1 and ITS2) revealed $F$. hepatica, F. gigantica and the intermediate form coexist in China [158-160,162,163]. However, the studies could not establish a clear geographic distribution of Fasciola spp. due to small sample size.

\subsection{Fasciolopsiasis}

\subsubsection{Parasite and Pathogenicity}

Human fasciolopsiasis results from consuming water plants with cysts from Fasciolopsis buski, the largest intestinal fluke parasitizing humans (Figure 6). Encystation was also observed on the surface of aquarium wall, stones and other objects [164]. Cysts can also float on the water surface. Therefore, drinking fresh water may be an alternative route of transmission of $F$. buski [164].

Figure 6. Life cycle of Fasciolopsis buski (Available online: http://commons.wikimedia.org/ wiki/File:Fasciolopsis_buski_LifeCycle.gif).

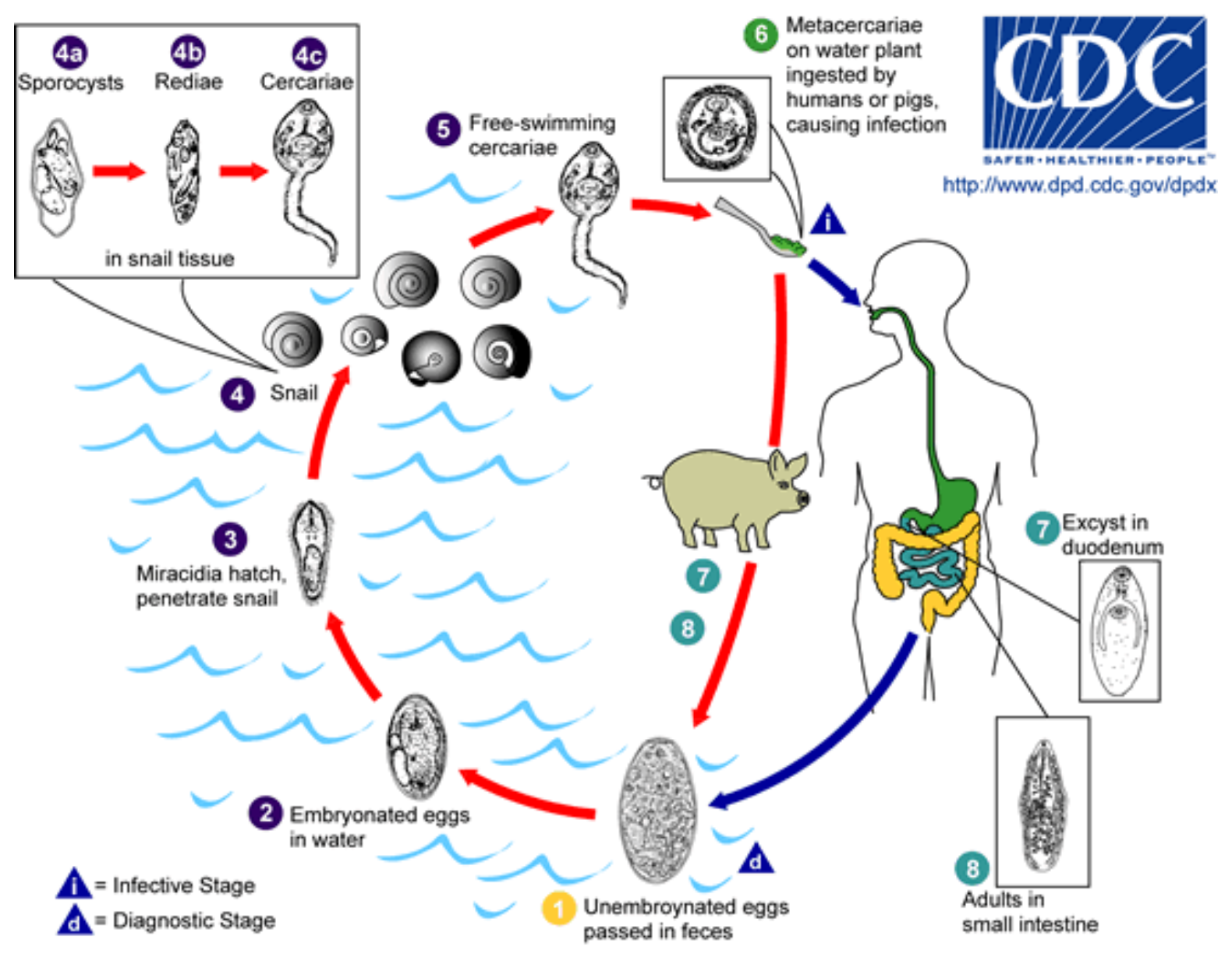

Adults reside in the small intestine, and Immature eggs are released in stool. Eggs become embryonated in water and release miracidia, which invade a suitable snail intermediate host. In the snail the parasites undergo several developmental stages (sporocysts, rediae, and cercariae). 
The cercariae are released from the snail and encyst as metacercariae on aquatic plants. The mammalian hosts become infected by ingesting metacercariae on the aquatic plants. After ingestion, the metacercariae excyst in the duodenum and attach to the intestinal wall. There they develop into adult flukes in approximately 3 months, attached to the intestinal wall of the mammalian hosts (humans and pigs). The adults have a life span of about one year.

The symptoms of fasciolopsiasis manifest after an incubation period of 1-3 months and depend on several factors including the worm burden and physiologic state of the patient (Table 10).

Table 10. Symptoms of Fasciolopsiasis dependent on worm burden.

\begin{tabular}{|c|c|}
\hline Worm Burden & Symptoms \\
\hline Mild infection & $\begin{array}{ll}\checkmark & \text { Abdominal pain } \\
\checkmark & \text { Diarrhea } \\
\checkmark & \text { Vomiting } \\
\end{array}$ \\
\hline Heavy infection & $\begin{array}{ll}\checkmark & \text { Abdominal obstruction } \\
\checkmark & \text { Obstructive jaundice, if worms ectopically lodge in the biliary system }\end{array}$ \\
\hline Prolonged infection & $\begin{array}{ll} & \text { Malnutrition symptoms: weight loss, anemia, edema, etc. } \\
\checkmark & \text { Stunting and mental retardation in children }\end{array}$ \\
\hline
\end{tabular}

\subsubsection{Epidemiology}

Many reports indicate that fasciolopsiasis was heavily endemic in southern China in the 1970s and 1980s. For example, a survey performed in 8 villages in Putian County, Fujian Province, showed that $55.1 \%$ of 1,834 participants were infected with $F$. buski [165]. In the same area, $41.9 \%$ of the pig population and $35.6 \%$ of the examined water chestnut samples were infected. In another study, the prevalence was $12.1 \%$ among 61,392 individuals in Jiangling County, Hubei Province [166]. The first national survey reported 2,353 cases across China, a national prevalence of $0.17 \%$ [4]. It was extrapolated that there were 1.91 million infections with this parasite in 17 provinces. Above-average prevalences were found in Hubei, Hunan, Jiangsu, Gansu and Jiangxi Provinces as well as in Shanghai; Hubei had the highest prevalence of $1.89 \%$ and the prevalence was highest in the age group 50-54 years [4]. F. buski prevalence did not differ between sex, but were related to profession; farmers were at the highest risk of infection [4]. Significantly above-average prevalences were found among the Tujia and Miao ethnic minority [4]. According to the results of the second national survey, F. buski had considerably lost prominence as a human parasite [3]. With the exception of Zhejiang and Henan Provinces, a general decline in prevalence was noted (Table 11). However, pockets of high endemicity persist, e.g., in Hunan Province where all patients originated from Hanshou County where the local prevalence was $0.39 \%$. Similarly, all infections detected in Shanghai originated from Chongming Island. 
Table 11. Endemic areas of fasciolopsiasis in China and change of prevalence between two national surveys.

\begin{tabular}{ccccccc}
\hline \multirow{2}{*}{ Province } & \multicolumn{3}{c}{ First National Survey } & \multicolumn{2}{c}{ Second National Survey } \\
\cline { 2 - 7 } & $\begin{array}{c}\text { No. } \\
\text { Examined }\end{array}$ & $\begin{array}{c}\text { No. } \\
\text { Infected }\end{array}$ & $\begin{array}{c}\text { Infection } \\
\text { Rate (\%) }\end{array}$ & $\begin{array}{c}\text { No. } \\
\text { Examined }\end{array}$ & $\begin{array}{c}\text { No. } \\
\text { Infected }\end{array}$ & $\begin{array}{c}\text { Infection } \\
\text { Rate (\%) }\end{array}$ \\
\hline Hubei & 53,382 & 1,002 & 1.877 & 15,524 & 1 & 0.006 \\
Shanghai & 62,134 & 482 & 0.776 & 11,372 & 2 & 0.018 \\
Hunan & 63,794 & 210 & 0.329 & 15,233 & 6 & 0.039 \\
Jiangsu & 62,699 & 181 & 0.284 & 14,700 & 3 & 0.020 \\
Jiangxi & 52,069 & 100 & 0.192 & 20,154 & 30 & 0.149 \\
Gansu & 28,700 & 54 & 0.188 & 9,255 & - & - \\
Guangxi & 51,883 & 58 & 0.112 & 13,990 & 1 & 0.007 \\
Anhui & 54,392 & 60 & 0.110 & 14,873 & 6 & 0.040 \\
Guangdong & 61,517 & 60 & 0.098 & 17,014 & - & - \\
Hainan & 7,958 & 6 & 0.075 & 7,924 & 0 & 0 \\
Zhejiang & 55,284 & 40 & 0.069 & 15,863 & 17 & 0.107 \\
Sichuan * & 97,222 & 57 & 0.059 & 81,359 & 0 & 0 \\
Fujian & 53,416 & 29 & 0.053 & 20,195 & + & + \\
Guizhou & 52,938 & 5 & 0.094 & 15,958 & - & - \\
Liaoning & 51,405 & 4 & 0.008 & 22,767 & - & - \\
Shandong & 87,825 & 4 & 0.005 & 15,152 & 0 & 0 \\
Henan & 85,554 & 1 & 0.001 & 25,894 & 2 & 0.008 \\
\hline
\end{tabular}

* including the number of participants from Chongqing which belonged to Sichuan Province during the first national survey and was an independent municipality during the second survey; - denoting the information is not known from available data; + denoting $F$. buski was detected from participants but no accurate figures can be obtained from the current data.

\subsubsection{Recent Advances in Research}

Although human $F$. buski infections may be common in rural areas, few specific surveys have been conducted over the past decade. Only severe or ectopic infections, such as anemia and oedema, biliary fasciolopsiasis and intestinal obstruction, got attention from clinicians [167-169]. Detection methods such as serological testing have been developed as an alternative for faeces examination; ELISA with adult antigen of $F$. buski to detect specific antibodies in human sera showed high sensitivity and specificity, and a low rate of cross reactions with schistosomes and Paragonimus spp. [170]. Additionally, gastroscopy was proposed to diagnose early stage-fasciolopsiasis infections: in one study, 13 patients were diagnosed with $F$. buski infection by gastroscopy while their stool samples were egg-negative [171].

\subsection{Clonorchiasis}

\subsubsection{Parasites and Pathogenicity}

Clonorchiasis is caused by a liver fluke, Clonorchis sinensis. The parasite is transmitted between snail, fish and mammals. Like Fasciola spp. aforementioned, adult worms of $C$. sinensis parasitize the 
biliary system of definitive hosts (human, cat, dog, etc.). The eggs are released with faeces to environment. Freshwater snail ingests the eggs and a few weeks later larvae develop into cercariae in the liver and are released from the snail body. Swimming cercariae invade fish and become metacercariae. The latter are infective for humans, dogs and cats.

The early stage of infection is normally asymptomatic, particularly in light infection. However, some patients can have symptoms associated with the inflammation in the liver and biliary ducts (Table 12). Chronic symptoms are mainly associated with dysfunction of biliary ducts and the gall bladder. Biliary obstruction can lead to jaundice. Bile stone or cholelithiasis is common outcome of chronic infection. $C$. sinensis also is one of the parasites that are confirmed as a cause of cancer; cholangiocarcinoma is the most significant a malignant outcome [172,173].

Table 12. Stages and Symptoms of Clonorchiasis.

\begin{tabular}{l|ll}
\hline Stages & Symptoms \\
\hline & $\checkmark$ & Fever \\
& $\checkmark$ & Abdominal pain \\
& $\checkmark$ & Diarrhea \\
Acute & $\checkmark$ & Rash \\
& $\checkmark$ & Malaise \\
& $\checkmark$ & Liver abscess \\
& $\checkmark$ & Jaundice \\
\hline & $\checkmark$ & Cholangitis \\
Chronic & $\checkmark$ & Cholecystitis \\
& $\checkmark$ & Cholelithiasis / bile stone \\
& $\checkmark$ & Pancreatitis \\
& $\checkmark$ & Cholangiocarcinoma \\
\hline
\end{tabular}

\subsubsection{Epidemiology}

It is estimated that worldwide 15.3 million people were infected by $C$. sinensis, of which $84.3 \%$ are distributed in China [174]. According to the second national survey, the overall prevalence was $0.58 \%$ in the country [3]. In 27 endemic provinces the prevalence was as high as $2.4 \%$ and the number of infected people was 12.5 million [3]. The most heavily endemic provinces were Guangdong (17.48\%), Guangxi (9.44\%) and Heilongjiang (4.54\%), which composed two hotspots in China, i.e., southern and northeast centers. The prevalence among males (2.94\%) was significantly higher than that among females (1.84\%), which correlated with the differences in eating habits [3]. The group aged 50-59 year had the highest prevalence $(9.16 \%)$.

Clonorchiais is an increasing public health concern in public health in China [175]. Firstly, infected population is rapidly growing. The prevalence increased by $75 \%$ from the first national survey $(0.33 \%)$ to the second national survey $(0.58 \%)$. Secondly, infection with $C$. sinensis is the most common cause for surgery due to hepatobiliary and pancreatic diseases in endemic areas [176]. There might be over 1,000 patients admitted to a local hospital in endemic areas every year [177]. Third, cholangiocarcinoma is a malignant outcome of $C$. sinensis infection. Nearly 1,000 cases due to C. sinensis infection are diagnosed annually in China, which may still an underestimate $[178,179]$. 


\subsubsection{Recent Advances in Research}

Bioinformatics is a hotspot in the field of $C$. sinensis-related research in recent years. An expression library for each stage of $C$. sinensis was established. Based on the libraries, individual genes and proteins of important function have been studied for diagnosis and drug targets. However, the conclusive findings have not been achieved. In 2011, the genome of $C$. sinensis has been published [180]. In-depth analysis will provide more insights for potential diagnosis and drug development.

Although most of infections may be asymptomatic, some can cause severe outcomes [175]. The large population with clonorchiasis imposes a huge disease burden on human health in China. To understand the burden, disability weight has been measured in a community-based study. The overall disability weights of the male and female were 0.101 and 0.050 , respectively [181]. The overall disability weights of the age group of 5-14, 15-29, 30-44, 45-59 and 60+ were 0.022, 0.052, 0.072, 0.094 and 0.118 , respectively [181]. The disease burden in the whole country should be estimated based on a clear epidemic profile.

Praziquantel is confirmed to be efficacious against clonorchiasis [182]. However, adverse events are frequently observed after praziquantel administration [182]. Tribendimidine, artemether and artesuante showed high effectiveness in $C$. sinensis-infected rats and in vitro and hence might be potential new drug candidates for treating infections [183]. Recently, the Chinese anthelmintic drug tribendimidine was demonstrated to be highly effective against human infections [184].

\subsection{Paragonimiasis}

\subsubsection{Parasites and Pathogenicity}

At least 29 species of Paragonimus have been described in China, among which 10 species are able to infect humans [4]. P. westermani and P. skrjabini (Pagumogonimus skrjabini) are the most common cause of human paragonimiasis. The life cycle of Paragonimus spp. involves three kinds of host. In mammalian definitive host, paired adult worms live in lung capsules. The eggs are released with sputum or swallowed and excreted in faeces. Hatched miracidiae penetrates the first intermediate host snail (Melania spp.), and ultimately develop into cercaria. Crustaceans (e.g., crabs and crayfish) serve as second intermediate hosts, which are infected via direct penetration of cercariae or ingestion of infected mollusks. Cercariae encyst and develop into metacercariae. Mammals acquire an infection by consuming raw or undercooked infected crustaceans. Metacercariae excyst in the small intestine and migrate through the intestinal wall to reach the abdominal cavity, enter the abdominal wall, and migrate to the pleural cavity.

Humans are permissive definitive hosts for several Paragonimus spp. and worms migrate along a mostly defined route to their final destination, the lung [185]. Therefore, the main symptoms are associated with lesions in the respiratory system. Common symptoms include cough, rusty sputum, etc. (Table 13) However, the central nervous system can also be involved if worms accidentally migrate through the soft tissues along the vessels of the neck and via the jugular foramen into the CNS [185]. Approximately $11.2-33.7 \%$ of Paragonimus spp. infections develop a cerebral involvement [3,186-188]. Cerebral paragonimiasis is potentially fatal [189]. 
Table 13. Stages and symptoms of Paragonimiasis.

\begin{tabular}{l|ll}
\hline Stages & Symptoms \\
\hline \multirow{3}{*}{ Acute } & $\checkmark$ & Abdominal pain \\
& $\checkmark$ & Diarrhea \\
& $\checkmark$ & Fever \\
\hline \multirow{2}{*}{ Chronic } & $\checkmark$ & Cough \\
& $\checkmark$ & Rusty sputum \\
\hline \multirow{3}{*}{ Infection outside respiratory } & $\checkmark$ & Symptoms related to eosinophilic meningitis \\
system & $\checkmark$ & Seizure \\
& $\checkmark$ & Paralysis \\
\hline & $\checkmark$ & Subcutaneous migratory swellings \\
\hline
\end{tabular}

\subsubsection{Epidemiology}

Paragonimus spp. was once widely distributed in China; 454 counties in 21 provinces were identified as endemic areas. Up to 1998, more than 23,000 human cases had been reported from 436 counties [3]. The main endemic area was localized at the middle reach of the Yangtze River. According to the second national survey, the serological prevalence of paragonimiasis was $1.71 \%$ $(1,163 / 68,209)$ [3]. However, only 31 cases were parasitological diagnosed and accounted for $0.05 \%$.

Paragonimiasis is a neglected parasitic disease. There is no specific control strategy for this disease up to date. Sporadic cases and even outbreaks were reported in recent years [190,191]. The symptoms due to Paragonimus infection resemble that of tuberculosis, a re-emerging infectious disease in China, and misdiagnosis is not uncommon. The absence of relevant knowledge in the clinical community is also challenging the control of paragonimiasis.

\subsubsection{Recent Advances in Research}

Traditionally, paragonimiasis is attributed to ingestion of raw or undercooked crabs. However, many patients deny the habit of eating raw or undercooked crabs. The probability of infection by drinking stream water contaminated with metacercariae is very low [192]. According to a recent report, cercariae successfully infected four dogs and one cat by feeding food with the parasite larvae [193]. This finding indicates that humans can possibly also be infected when drinking stream water contaminated with not metacercariae but cercariae. Of note, the density of cercariae can be much higher than that of metacercariae in stream water.

Approximately 30 species of Paragonimus have been recorded in China. Recently, new species of Paragonimus as well as snail and crab hosts have been identified [194-198], indicating a complex phylogeny of the parasite and hosts. The validity of a species should be based on not only morphology but also molecular difference as well as ecological characteristics. However, molecular researches pertaining to the taxonomy of parasite and intermediate hosts are rare [199,200]. In addition, the worm specimens from patients are rarely identified by molecular tools. The exact number of species that can infect humans thus remains unknown. Therefore, the molecular tools should be applied to systematic studies regarding the phylogeny of Paragonimus as well as host animals in the near future, which in turn will help to understand the pathogenicity in humans. 


\subsection{Control Strategies for Water-Related Diseases}

The majority of all human parasitic infections are diseases of poverty with a strong environmental component. Therefore, urbanization and socioeconomic development which have improved the living conditions of many Chinese have contributed to decrease of the prevalence of parasitic diseases so that they are no longer major public health problems. However, the burden due to parasitic diseases is still considerable in certain areas and populations across China, owing to the inequality in economic development, public services including health care and preventive medicine, and environmental conditions. Of note, many policies conceived for the economic development of the country, particularly those aimed at the countryside and relatively poor regions, significantly impact the epidemiology of parasitic diseases; even if they were not conceived to directly control them. In addition, numerous targeted measures for diseases control mentioned below are being implemented.

\subsubsection{Legal Framework}

The "Law of the People's Republic of China on the Prevention and Treatment of Infectious Diseases" was issued in 1989 and amended in 2004. Aimed at the control of infectious diseases, it mandates that medical personnel with knowledge about individuals with any of the six designated parasitic diseases, namely amoebiasis dysentery, schistosomiasis, malaria, leishmaniasis, echinococcosis and filariasis, are obliged to report all cases via the national reporting system. The responsible national-level public health departments then respond to these reports and initiate appropriate steps and interventions. The reporting system has greatly facilitated the identification of outbreaks and monitoring of trends in prevalence and incidence. Furthermore, the "Schistosomiasis Prevention and Control Regulation" was issued in 2006, mandating a coordinated effort by several departments of the central and local governments to guarantee the full implementation of the comprehensive control strategy [2].

\subsubsection{Water Supply and Sanitation}

Awareness and concern for public health are rapidly increasing in China. A reliable supply of clean drinking water in adequate amounts is now widely demanded as a basic service, albeit still not available to millions of inhabitants. The new "National Drinking Water Criteria (GB5749-2006)" were published in 2006 and list Cryptosporidium spp. and G. intestinalis as indicators for water quality. The current limit to consider drinking water as safe for human consumption is a concentration of less than one G. intestinalis cyst or Cryptosporidium oocyst per $10 \mathrm{~L}$ water. Standard examination methods for water samples are also provided. In urban areas, utilities have taken the new criteria into account. The possibility of schistosomiasis japonica transmission and the expansion of the endemic area have become elements of environmental and health impact assessments of water resource management projects such as the South-North Water Transfer Project and the Three Gorges Dam [201-203].

Sanitation and the proper management of wastewater are important elements for ensuring the supply of clean drinking water. Improving sanitation includes the construction of latrines or water-flush toilets and sewers, the collection of wastewater of domestic and industrial origin and its separation from environmental water bodies, and waste water treatment. Almost all studies on the effect of latrine construction and usage demonstrate their effectiveness in reducing the prevalence of different 
water-based and -related infectious diseases [204,205]. However, latrine construction is seldom considered as an independent control tool but implemented in the frame of general development and urban or rural rehabilitation programs. There are currently no national laws or criteria for faeces management in China. Still, more and more sewage treatment plants are constructed based on local regulations and initiative, especially in urban areas. In rural areas, septic tanks and biogas facilities at household or community level are promoted. They not only provide gas as a substitute fuel but also sterilize the sludge, including parasite eggs [204].

\subsubsection{Innovative Approaches for the Control of Water-Related Parasitic Infections}

Diseases occur in a complex socio-ecological context characterized by feedback loops across space and time, self-organization, holarchies, and sudden changes in organization when thresholds are reached [206]. Therefore, single-minded control programs usually fail to effectively control the target disease. A sustainable control strategy must incorporate multiple scales and perspectives, and high degrees of uncertainty [206]. The comprehensive strategy for the control of schistosomiasis japonica that is promoted in China illustrates this ecosystem-based approach [132]. The measures include replacing labor animals with machines, prohibiting the grazing of cattle in grasslands adjacent to water bodies, supplying tap water, constructing latrines and the promotion of biogas pools. Community-based health education and synchronous praziquantel-based chemotherapy for all villagers and their cattle are implemented in order to rapidly decrease the prevalence. The new control strategy eschews the use of chemical molluscicides, which have proven to result in environmental pollution and damage [207].

\section{Conclusions}

Water-related parasitic diseases have generally declined in China. This has often been attributed to socioeconomic development, which has improved living conditions and alleviated the financial burden due to parasitic diseases in many areas. However, some parasitic diseases still occur at considerable prevalence in certain areas and populations, owing to the heterogeneity in natural conditions and economic development and the inequity of access to public services including preventive and curative health care. Emerging and re-emerging pathogens and risk factors are also challenging the achievements made with regard to the control of parasitic diseases [208]. The growing population of immunocompromised individuals due to HIV, chronic diseases, cancer and immunosuppressive drugs is vulnerable to opportunistic parasite infections, such as cryptosporidiosis and cyclosporiasis.

The majority of all parasitic infections are diseases of poverty [1]. However, some parasitic diseases, especially helminthiases, occur in a complicated context and call for ecosystem-based approaches. Controlling major sources of infection including humans and animals, changing land-use patterns, and adapting to climate change are important components of ecosystem-based inventions.

\section{Acknowledgments}

We are obligated to editors and referees for their comments, especially for their constructive suggestions pertaining to tables and figures. 


\section{Conflict of Interest}

The authors declare no conflict of interest.

\section{References}

1. Zhou, X.N. Prioritizing Research for "One health-One world". Inf Dis Poverty 2012, 1, 1.

2. Huntington, D. Health systems perspectives-Infectious diseases of poverty. Inf. Dis. Poverty 2012, $1,12$.

3. Wang, L.D. Report on the National Survey of Current Status of Major Human Parasitic Diseases in China; People's Medical Publishing House: Beijing, China, 2008.

4. Xu, L.Q.; Yu, S.H.; Xu, S.M. Distribution and Pathogenic Impact of Human Parasites in China; People's Medical Publishing House: Beijing, China, 1999.

5. WHO. Amoebiasis. Wkly. Epidemiol. Rec. 1997, 72, 97-99.

6. Cox, F.E. History of human parasitology. Clin. Microbiol. Rev. 2002, 15, 595-612.

7. Garcia, L.S. Laboratory identification of the Microsporidia. J. Clin. Microbiol. 2002, 40, 1892-1901.

8. Diamond, L.S.; Clark, C.G. A redescription of Entamoeba histolytica Schaudinn, 1903 (Emended Walker, 1911) separating it from Entamoeba dispar Brumpt, 1925. J. Eukaryot. Microbiol. 1993, 40, 340-344.

9. $\quad$ Reed, S.L. Amebiasis: An update. Clin. Infect. Dis. 1992, 14, 385-393.

10. Tu, X.G.; Yao, L.N.; Huang, X.M.; Chen, H.L.; Yu, K.G.; Jiang, M.G.; Zhu, W.M.; Chen, Y.M.; Liu, B.D.; Lei, C.Q. Second sampled survey on the distribution of human parasites in Zhejiang province. Chin. J. Parasitol. Parasit. Dis. 2001, 19, 145-148.

11. Xu, B.L.; Zhao, X.D.; Su, Y.P.; Li, H.; He, L.J.; Lin, X.M.; Yan, Q.Y.; Huang, Q.; Yan, X.X.; Liu, H. Survey on present epidemic status of main human parasites infection in Henan province. Chin. J. Parasit. Dis. Control. 2005, 18, 454-457.

12. Wei, Q.K.; Xu, F.Q.; Huang, B.C.; Cheng, P.; Shi, F.M.; Zhang, Z.H.; Fu, T.X.; Zou, E.S.; Tan, W.B.; Xu, X.L. Analysis of the infectious status of children with intestinal protozoa during 1981-2000 in Jining city. Chin. Trop. Med. 2003, 3, 758-760.

13. Chen, H.; Li, C.H.; Xie, M.L.; Wei, X.Y.; Yao, L.J. The relationship between diarrhea and infection of intestinal protozoa in Fuzhou district. Strait J. Prev. Med. 2002, 8, 14-16.

14. Liu, S.W.; Chen, F.L. Epidemiological analysis of amebic dysentery in Qiaotou township of Dongguan city in 2004. Chin. Trop. Med. 2005, 5, 1461-1462.

15. Mao, L.X.; Zheng, J.J.; Wang, X.M.; Yao, L.N.; Cheng, H.L.; Zhu, Q.G. Epidemiological investigation on an outbreak of amoebic dysentery in Jiangshan city of Zhejiang province. Chin. J. Parasitol. Parasit. Dis. 2009, 27, 182-183.

16. Tian, L.G.; Steinmann, P.; Chen, J.X.; Chen, S.H.; Zhou, X.N. HIV/AIDS, parasites and co-infections: Publication patterns in China. Parasit. Vectors 2009, 2, doi: 10.1186/1756-3305-2-31.

17. Chen, Y.; Zhang, Y.; Yang, B.; Qi, T.; Lu, H.; Cheng, X.; Tachibana, H. Seroprevalence of Entamoeba histolytica infection in HIV-infected patients in China. Am. J. Trop. Med. Hyg. 2007, 77, 825-828. 
18. Yang, G.Y.; Huang, D.C.; Jiang, B.; Niu, L.L.; Wang, Q.; Yu, M.X.; Zhao, B.; Deng, J.B.; Chen, W.G. Identification and culture of Entamoeba histolytica isolated from Manouria impressa. Chin. J. Prev. Vet. Med. 2007, 29, 248-251.

19. Niu, L.L.; Wang, Q.; Yang, G.Y.; Huang, D.C.; Jiang, B.; Zhao, B.; Yu, X.M.; Deng, J.B.; Chen, W.G. Patho-histological observation of Manouria impressa with Entamoeba histolytica. Vet. Sci. Chin. 2006, 36, 478-481.

20. Sun, X.D.; Manue, S.; Zhang, X.Y.; Liu, H.; Deng, Y.; Yang, Y.M.; Wang, L.B.; Li, C.F.; Guo, X.F.; Zhang, C.L. Epidemiological survey of amoebiasis by using TECHLAB E. histolytica II ELISA kits. Chin. Trop. Med. 2006, 6, 1931-1932.

21. Zengzhu, G.; Bracha, R.; Nuchamowitz, Y.; Cheng, I.W.; Mirelman, D. Analysis by enzyme-linked immunosorbent assay and PCR of human liver abscess aspirates from patients in China for Entamoeba histolytica. J. Clin. Microbiol. 1999, 37, 3034-3036.

22. Solaymani-Mohammadi, S.; Coyle, C.M.; Factor, S.M.; Petri, W.A., Jr. Amebic colitis in an antigenically and serologically negative patient: Usefulness of a small-subunit ribosomal RNA gene-based polymerase chain reaction in diagnosis. Diagn. Microbiol. Infect. Dis. 2008, 62, 333-335.

23. Thompson, R.C. Giardiasis as a re-emerging infectious disease and its zoonotic potential. Int. J. Parasitol. 2000, 30, 1259-1267.

24. Hunter, P.R.; Thompson, R.C. The zoonotic transmission of Giardia and Cryptosporidium. Int. J. Parasitol. 2005, 35, 1181-1190.

25. Traub, R.J.; Monis, P.T.; Robertson, I.; Irwin, P.; Mencke, N.; Thompson, R.C. Epidemiological and molecular evidence supports the zoonotic transmission of Giardia among humans and dogs living in the same community. Parasitology 2004, 128, 253-262.

26. Luo, R.D. Clinical analysis of 7 cholecystitis cases due to giardiasis. Guangzhou Med. J. 1996, $27,41-42$.

27. Tu, J.; Zhang, Y.L.; Wang, L.; Wu, T.J. A case of Giardia lamblia infection with cholecystitis and persistent fever. J. Appl. Clin. Pediatr. 2002, 17, 232.

28. Yang, F.; Xu, J.; Zhang, J. Clinical analysis of 26 pediatric patients with cholecystitis due to Giardia lamblia. J. Appl. Clin. Pediatr. 1990, 5, 23.

29. Lopez, J.J.; Wright, J.A.; Hammer, R.A.; Ertan, A. Chronic pancreatitis is associated with a high prevalence of giardiasis. Can. J. Gastroenterol. 1992, 6, 73-76.

30. Cao, J.H.; Chen, Z.Z.; Rong, D.N.; Li, F. Case report: Discovery of Giardia lamblia from pleural effusion. Chin. J. Lab. Med. 2006, 21, 491.

31. Wu, F.Y.; Liu, M.F. Case report: Discovery of Giardia lamblia from ascites. Sichuan Med. 1996, 17, 198.

32. Gao, S.W.; Wang, X.G.; Wang, X.Q.; Chen, C.J. Case report: Giardia lamblia infection in joints and peripheral soft tissue. Chin. J. Radiol. 1996, 30, 252.

33. Meng, X.Y.; Wang, D.N.; He, S.Y. Fatal case due to Giardia lamblia infection. New Med. 1981, 12, 461-462.

34. Giboda, M.; Viengsay, M.; Bouaphan, S.; Ditrich, O. Epidemiology of intestinal parasitosis in Laos (with anti-amoebic antibody levels). Bull. Soc. Pathol. Exot. 1991, 84, 184-193. 
35. Steinmann, P.; Du, Z.W.; Wang, L.B.; Li, H.J.; Chen, S.R.; Yang, Z.; Fan, W.; Jia, T.W.; Li, L.H.; Vounatsou, P.; et al. Extensive multiparasitism in a village of Yunnan province, People's Republic of China, revealed by a suite of diagnostic methods. Am. J. Trop. Med. Hyg. 2008, 78, 760-769.

36. Jin, Q.Q.; Yu, K.M.; Tang, L.F.; Tian, C.L.; Lu, Z.C. Investigation of infectious status of Blastocystis hominis in 1,354 outpatients. Chin. Trop. Med. 2005, 5, 1469-1471.

37. Chang, H.; Cao, M.F.; Hu, D.S.; Wu, S.B.; Zhang, Y.Q. Case report: Tonsillitis due to Giardia lamblia. J. Clin. Otorhinolaryngol. Head Neck Surg. 2009, 23, 716.

38. Quan, T.T. Discovery of Giardia lamblia in bile. Med. J. Natl. Def. Forces Southwest China 2009, 19, 587.

39. Hou, L.N.; Liang, K.Z.; Gao, C.F. Giardia lamblia infection in gallbladder cancer: A case report. Acad. J. Second Mil. Med. Uni. 2007, 28, 1305.

40. Tian, Z.C.; Zhang, X.C. The discovery of virus from Giardia lambia in China. Chin. J. Vet. Sci. 2003, 23, 42 .

41. Tian, Z.C.; Zhang, X.C.; Li, J.H.; Yin, J.G.; Yang, J. Clone and sequencing of cDNA of complete genome of Giardia lamblia-virus. Chin. J. Vet. Sci. 2003, 23, 573-575.

42. Bai, X.H.; Zeng, L.; Zhu, B.; Wang, H.L. Existence of Cryptosporidium and Giardia in the effluent from a WWTP and its receiving water in Shanghai. Chin. J. Health Lab. Technol. 2006, $16,4-5$.

43. Wang, X.Y.; Li, Y.H.; Yu, S.Y.; Li, S.G.; Wang, B. Investigation on contamination of Cryptosporidium parvum and Giardia lamblia in surface water in Shengzhen. Chin. J. Public Health Manag. 2006, 22, 259-261.

44. Cai, J.; Ye, J.; Du, H.L.; Hu, X.W.; Liu, J.; Huang, W.; Cui, X. Investigation of Cryptosporidium and Giardia contaminating drinking-water in Chengdu. Chin. J. Health Lab. Technol. 2007, 17, 2165-2167.

45. Andrews, R.H.; Adams, M.; Boreham, P.F.; Mayrhofer, G.; Meloni, B.P. Giardia intestinalis: Electrophoretic evidence for a species complex. Int. J. Parasitol. 1989, 19, 183-190.

46. Lu, S.; Li, J.; Zhang, Y.; Wen, J.; Wang, F. The intraspecific difference of the triose phosphate isomerase (tim) gene from Giardia lamblia. Chin. Med. J. 2002, 115, 763-766.

47. Wen, S.F.; Lu, S.Q.; Feng, X.M.; Wang, F.Y. Molecular phylogeny of Giardia lamblia based on ITS1-5.8SrRNA-ITS2 sequence. Curr. Zool. 2006, 52, 954-958.

48. Wang, A.L.; Wang, C.C. Viruses of parasitic protozoa. Parasitol. Today 1991, 7, 76-80.

49. Wang, A.L.; Wang, C.C. Discovery of a specific double-stranded RNA virus in Giardia lamblia. Mol. Biochem. Parasitol. 1986, 21, 269-276.

50. Chen, L.F.; Li, J.H.; Zhang, X.C.; Liu, Q.; Zhao, Y.P.; Cao, L.L.; Chen, C. The analysis of full length cDNA sequence of Giardia canis virus Changchun strain. Acta. Vet. Zootech. Sin. 2006, 37, 408-411.

51. Tian, Z.C.; Zhang, X.C.; Li, J.H.; Yi, J.G.; Yang, J. The expression of GLV1518-2322 gene from Giardiavirus in Giardia lamblia isolated from human in China and the preparation of its antibodies. Acta. Parasitol. Med. Entomol. Sin. 2004, 11, 5-7.

52. Marshall, M.M.; Naumovitz, D.; Ortega, Y.; Sterling, C.R. Waterborne protozoan pathogens. Clin. Microbiol. Rev. 1997, 10, 67-85. 
53. Meisel, J.L.; Perera, D.R.; Meligro, C.; Rubin, C.E. Overwhelming watery diarrhea associated with a Cryptosporidium in an immunosuppressed patient. Gastroenterology 1976, 70, 1156-1160.

54. Nime, F.A.; Burek, J.D.; Page, D.L.; Holscher, M.A.; Yardley, J.H. Acute enterocolitis in a human being infected with the protozoan Cryptosporidium. Gastroenterology 1976, 70, 592-598.

55. Dang, H.L.; He, G.S.; Zhang, L.X.; Cao, J.; Jin, H.Y.; Yu, J.Y.; Zhu, S.H.; Huang, Y.; Xu, M.Q. Investigation on the prevalence of Cryptosporidium in reptiles and amphibians in Shanghai. Chin. J. Zoonoses 2008, 24, 179-181.

56. Lu, Q.B.; Chou, S.X.; Ru, B.R.; Liu, W.; Wang, S.M.; Miao, T.; Wang, Y.; Duan, Z.X.; Ning, C.S.; Zhang, L.X. Epidemiological investigation of cryptosporidiosis in dairy calves in some prefectures of Henan province. Chin. Vet. Sci. 2008, 38, 261-267.

57. $\mathrm{Xu}, \mathrm{T} . \mathrm{S}$. Epidemiological investigation of Cryptosporidium from poultry in Shandong province. Chin. J. Vet. Med. 2009, 45, 3-5.

58. Deng, M.; Rutherford, M.S.; Abrahamsen, M.S. Host intestinal epithelial response to Cryptosporidium parvum. Adv. Drug Deliv. Rev. 2004, 56, 869-884.

59. Han, F.; Tan, W.X.; Zhou, X.L. Two case reports of cryptosporidiosis in Nanjing. Jiangsu Med. J. 1987, 13, 692 .

60. Lu, S.H.; Lin, A.F.; Chen, R.; Wen, L.Y.; Chen, C.H.; Cheng, Y.Z.; Chen, X.J.; Zhu, G. The diagnosis and analysis of Cryptosporidium infection in children of Zhejiang Province. Chin. J. Zoonoses 2005, 16, 42-44.

61. Du, X.L.; Ge, J.J.; Qin, Y.F.; Meng, R.; Liu, Y.; Chu, K.; Hou, M.; Yang, P.S.; Wu, H.W. The epidemiological study on cryptosporidiosis in outpatients of Nanjing Children's Hospital. J. Trop. Med. 2009, 9, 382-385.

62. Lu, J.; Li, C.P. The survey of Cryptosporidium infection among young children in kindergartens in Anhui Province. Chin. J. Parasitol. Parasit. Dis. 2004, 22, 331-333.

63. Yue, X.H.; Wang, H.; Gou, J.Z.; Chen, X.C.; Yang, G.L.; Yang, Q.T.; Li, X.H.; Zhou, B.P.; Li, H.Q.; Cai, W.P. Investigation of Cryptosporidium parvum infection in AIDS patients in Guangdong and Yunnan provinces. Chin. J. Exp. Clin. Virol. 2008, 22, 339-341.

64. Xin, L.; Cui, W.; Liang, R.W.; Ji, R.; Sun, X.N.; Li, R.F. Investigation on the infection of Cryptosporidium among malignant tumor patients. J. Pathogen Biol. 2007, 2, 307-308.

65. Shen, L.J.; Li, W. Investigation on Cryptosporidium infection among injection drug users in Dali. Chin. J. Public Health 2005, 21, 1295-1296.

66. Huang, M.Z.; Guan, L.; Xie, M.Z.; Li, D.Q.; Zhou, J.; Li, Z.Y.; Liu, H.; Dai, W.P. Study on condition of Cryptosporidium infection among male drug users in detoxification institute in Changsha city. Chin. J. Public Health 2003, 19, 301-303.

67. Zhu, H.S.; Du, X.L.; Yu, R.B.; Xu, J.M.; Zhu, L.F.; Wu, H.W. Serum immunology investigation of Cryptosporidium infection among injection drug abusers. Chin. J. Schistosom. Contr. 2008, 20, 364-366.

68. Fan, B.; He, X.Y.; Huang, Z.M.; Wang, W.L.; Bo, W.F.; Su, Q. Epidemiological investigation of cryptosporidiosis in Yuxi district. Chin. J. Pest Contr. 1992, 8, 228-230.

69. Su, Y.P.; He, L.J.; Song, J.D.; Zhang, K.R.; Lu, L.F.; Zhang, Q.F. Cryptosporidium infection among children in Henan province. Chin. J. Parasit. Dis. Contr. 1993, 5, 313. 
70. Zhao, X.N.; Zhang, D.M.; Zhang, L.X.; Liu, X.M. Cryptosporidium infections among children in Helongjiang province. Chin. J. Zoonoses 1998, 14, 73-74.

71. Xing, W.L.; Yang, L.; Liang, S.H.; Liu, Q.Z.; Zheng, X.Y. Cryptosporidiosis in patients with diarrhea in Wenzhou district. J. Wenzhou Med. Coll. 1999, 29, 117-118.

72. Lu, S.H.; Lin, A.F.; Chen, R.; Wen, L.Y.; Chen, C.H.; Cheng, Y.Z.; Chen, X.J.; Zhu, G. The diagnosis and analysis of Cryptosporidium infection in children of Zhejiang province. Chin. J. Zoonoses 2000, 16, 42-44.

73. Zhang, Y.J.; Luo, P.; Gao, R. Cryptosporidium infection among children with diarrea in a child hospital in Chengdu city. J. Prac. Parasit. Dis. 2001, 9, 72-73.

74. Chen, H.; Mao, X.R.; Ling, X.M.; Song, J.J. Investigation on Cryptosporidium infection in population in three districts of Gansu province. Chin. J. Parasitol. Parasit. Dis. 2001, 19, 112.

75. Luo, W.P.; Li, B.S.; Luo, L.; Tong, S.X.; Liu, Y.; Suo, F.Y.; Dong, Q.; Wang, L. Primary investigation on Cryptosporidium in patients with diarrea in Urumqi. End. Dis. Bull. 2002, 17, 93.

76. Zhang, B.X.; Yu, H.; Zhang, L.L.; Tao, H.; Li, Y.Z.; Li, Y.; Cao, Z.K.; Bai, Z.M.; He, Y.Q. Prevalence survey on Cyclospora cayetanensis and Cryptosporidium ssp. in diarrhea cases in Yunnan province. Chin. J. Parasitol. Parasit. Dis. 2002, 20, 106-108.

77. Cai, R.; Li, C.P.; Wang, J.; Xu, L.F.; He, J. An epidemiological survey of cryptosporidiosis with diarrhea in Huainan area. J. Trop. Med. Parasitol. 2003, 1, 26-28.

78. Xu, H.Z.; Lin, G.H.; Meng, J.F.; Huang, Z.M. Cryptosporidium infection in Longhai city. Chin. J. Zoonoses 2005, 21, 282.

79. Niu, Y.; Li, R.H.; Yu, X.H. Primary investigation of Cryptosporidium infection in diarrhea patients in Qiqihar district. J. Qiqihar Med. Coll. 2006, 27, 184-185.

80. Zhou, Y.X. Investigation on Cryptosporidium infection among diarrea patients in Heze city during 2002-2003. End. Dis. Bull. 2006, 21, 38.

81. Li, Y.; Bin, Y.Y.; Cong, F.; An, C.L. Cryptosporidium infection in humans in Shenyang district. Chin. J. Zoonoses 2006, 22, 473-474.

82. Shen, J.P.; Ge, J.J. Cryptosporidiosis among 2018 children in kindergartens. J. Appl. Clin. Pediatr. 1991, 6, 132.

83. Xu, Y.G.; Yao, F.B. Human cryptosporidiosis in Xuzhou and Huaiyin districts, Jiangsu province. J. Parasit. Dis. Contr. 1991, 4, 42-43.

84. Gong, Y.X.; Cao, S.Q.; Shi, X.Z.; Zhou, S.C.; Liu, Y.X. An investigation of Cryptosporidium infection among children. Acta Acad. Med. Qingdao 1992, 28, 144-146.

85. Lu, L.A.; LI, c.c.; Fan, Z.Z.; Chen, Y.L. The discovery of zoonotic cryptosporidiosis and epidemiological investigation in Hunan province. Chin. J. Zoonoses 1992, 8, 43-44.

86. Chen, Y.G.; Guo, H.S.; Dai, X.M.; Yao, F.B.; Shi, W.S.; Lu, M. Cryptosporidium infection in infants and children of Jiangsu province. J. Xuzhou Med. Coll. 1993, 13, 1-4.

87. Wang, Q.J.; Zhang, J. Cryptosporidium infections among 1124 children in Talimu district, Xinjiang province. Xijiang Med. J. 1995, 25, 187-188.

88. Cui, W.; Liang, R.W.; Wang, Z.Z. The investigation of children Cryptosporidium parvum infection and epidemiology in Weifang south mountains area. J. Weifang Med. Coll. 2001, 23, 11-12. 
89. Wang, H.Y.; Rong, J.Q.; Wu, G.P. Investigation on cryptosporidiosis in some southern areas of Guizhou province. J. Trop. Med. 2006, 6, 717-718.

90. Zhu, M.S.; Song, M.H. Cryptosporidium infection among school students in Shiyan district. Chin. J. Sch. Health 2007, 28, 549.

91. Zhu, M.S.; Song, M.H. Cryptosporidium infection among young children in kindergartens in Shiyan district. Chin. J. Sch. Health 2007, 28, 1040.

92. Zhu, M.S.; Zhu, J.; Wang, S.J.; Song, M.H. A survey of Cryptosporidium infection among humans being in Shiyan, China. J. Path. Biol. 2009, 4, 685-686.

93. Wang, L.W.; Yan, G. Advanced on epidemiology and treatment of cryptosporidiosis. J. Pathogen. Biol. 2008, 3, 953-956.

94. Tian, L.G.; Zhou, X.N. The neglected intestinal parasite co-infection with AIDS. Chin. J. Parasitol. Parasit. Dis. 2008, 26, 376-381.

95. Wang, Q.; An, C.X.; Guan, F.C.; Zhu, J.J.; Ning, C.S.; Zhang, L.X. Advances in study of genotype marker of Cryptosporidium. Chin. J. Zoonoses 2010, 26, 279-282.

96. Zhou, C.X.; He, G.S.; Zhang, L.X. Research on the identification technique of the species and genotype of Cryptosporidium in water. Chin. J. Animal Infect. Dis. 2009, 17, 81-86.

97. Song, D.; Huang, Y.; He, G.S.; Yang, L.R. The progress of research for detective method on Cryptosporidium. J. Inner Mongolia Agric. Uni. 2008, 29, 216-220.

98. Ortega, Y.R.; Sterling, C.R.; Gilman, R.H.; Cama, V.A.; Diaz, F. Cyclospora species-A new protozoan pathogen of humans. N Engl. J. Med. 1993, 328, 1308-1312.

99. Ortega, Y.R.; Gilman, R.H.; Sterling, C.R. A new coccidian parasite (Apicomplexa: Eimeriidae) from humans. J. Parasitol. 1994, 80, 625-629.

100. Shlim, D.R.; Cohen, M.T.; Eaton, M.; Ramachandran, R.; Long, E.G.; Ungar, B.L.P. An alga-like organism associated with an outbreak of prolonged diarrhea among foreigners in Nepal. Am. $J$. Trop. Med. Hyg. 1991, 45, 383-389.

101. Huang, P.; Weber, J.T.; Sosin, D.M.; Griffin, P.M.; Long, E.G.; Murphy, J.J.; Kocka, F.; Peters, C.; Kallick, C. The first reported outbreak of diarrheal illness associated with Cyclospora in the United States. Ann. Intern. Med. 1995, 123, 409-414.

102. Hoge, C.W.; Shlim, D.R.; Rajah, R.; Triplett, J.; Shear, M.; Rabold, J.G.; Echeverria, P. Epidemiology of diarrhoeal illness associated with coccidian-like organism among travellers and foreign residents in Nepal. Lancet 1993, 341, 1175-1179.

103. Su, Q.P.; Lin, Q.J.; Chen, J.L. The first case of cyclosporiasis in China. Chin. J. Zoonoses 1995, $11,6-7$.

104. Zhang, B.X.; Yu, H.; Zhang, L.L.; Tao, H.; Li, Y.Z.; Li, Y.; Cao, Z.K.; Bai, Z.M.; He, Y.Q. Prevalence survey on Cyclospora cayetanensis and Cryptosporidium ssp. in diarrhea cases in Yunnan province. Chin. J. Parasitol. Parasit. Dis. 2002, 20, 106-108.

105. Chen, X.Y.; Xu, L.F. The infection of Cyclospora on diarrhea children patients in one city. Chin. J. Sch. Health 2006, 27, 817-818.

106. Xing, W.L.; Wu, K.W.; Lin, X.Y.; Huang, H.C.; Liu, Q.Z.; Zheng, X.Y.; Jin, Y.G. Survey on Cyclospora infection among diarrheal patients in Whenzhou. Chin. J. Parasit. Dis. Control. 2002, 15, 320. 
107. Wang, K.X.; Li, C.P.; Wang, J.; Tian, H. A survey on Cyclospora infection in different population in Anhui province. Chin. J. Epidemiol. 2003, 24, 93.

108. Ge, J.J. Cyclosporiasis in children misdiagnosed as general enteritis. Clin. Misdiagn. Misther. 1998, $11,162$.

109. Zhou, Y.; Wang, Q.; Lv, B.; Qi, M.; Guan, F.C.; Zhang, L.X. Advances in epidemiology, taxology and genetics of Cyclospora. Chin. J. Zoonoses 2009, 25, 283-287.

110. Ge, J.J.; Shen, J.P.; Jiang, X.R. The infection model of Cyclospora cayetanensis in rats. Jiangsu Health Care 2000, 2, 54-55.

111. Xu, L.F.; Li, C.P. Study on the expression of immune function in cases infected by Cyclospora cayetanensis. Chin. J. Parasitol. Parasit. Dis. 2006, 24, 77-78.

112. Xu, L.F.; Sun, S.C. Logical qualitative research on the change of T cell subsets counts in the patients with Cyclospora cayetanensis. Chin. J. Health Lab. Technol. 2005, 15, 910-911.

113. Stenzel, D.J.; Boreham, P.F. Blastocystis hominis revisited. Clin. Microbiol. Rev. 1996, 9, 563-584.

114. Tan, K.S.; Singh, M.; Yap, E.H. Recent advances in Blastocystis hominis research: Hot spots in terra incognita. Int. J. Parasitol. 2002, 32, 789-804.

115. Li, L.H.; Zhang, X.P.; Lv, S.; Zhang, L.; Yoshikawa, H.; Wu, Z.; Steinmann, P.; Utzinger, J.; Tong, X.M.; Chen, S.H.; et al. Cross-sectional surveys and subtype classification of human Blastocystis isolates from four epidemiological settings in China. Parasitol. Res. 2007, 102, 83-90.

116. Xie, Z.J.; Zhang, R.Q.; Huang, W.F.; Liao, Y.G.; Su, S.L. Infection status and clinical analysis of Blastocystis hominis in adult diarrheal patients in Ganzhou. J. South. Med. Univ. 2008, 28, 1035-1036.

117. Liu, Y.; Qian, C.; Chen, X.R.; Zeng, D.Q.; He, A.J.; Yang, Y.H.; Lu, Z.C.; Liu, D.Y. Investigation of Blastocystis hominis from 180 patients. Appl. Prev. Med. 2008, 14, 285-286.

118. Wu, G.H.; Xiong, Y.S.; Cao, G.L.; Li, G.M.; Liu, M.Z.; Zhu, J.L. An outbreak of Blastocystosis. hominis. Chin. J. Parasit. Dis. Control. 2000, 13, 25-27.

119. Da, R.; Qiao, J.Y.; Lu, Z.H.; Li, X.Q.; Li, Y.Q.; Wang, W. Observation on the growth status of Blastocystis hominis in different mediums. J. Pathogen Biol. 2006, 1, 132-134.

120. Li, L.H.; Zhou, X.N.; Du, Z.W.; Wang, X.Z.; Wang, L.B.; Jiang, J.Y.; Yoshikawa, H.; Steinmann, P.; Utzinger, J.; Wu, Z.; et al. Molecular epidemiology of human Blastocystis in a village in Yunnan province, China. Parasitol. Int. 2007, 56, 281-286.

121. He, L.J.; Su, Y.P.; Yan, Q.Y.; Zhu, X.P.; Liu, H. Study on morphology and pathogenicity of Blastocystis hominis. Chin. J. Parasit. Dis. Control. 1999, 12, 195-196.

122. Jin, Q.Q.; Tang, G.D.; Yu, K.M. Measurement of impair and cytokines in intestinal mucous membrane in patients with Blastocystis hominis. Chin. J. Parasit. Dis. Control. 2005, 18, 352-354.

123. Boorom, K.F.; Smith, H.; Nimri, L.; Viscogliosi, E.; Spanakos, G.; Parkar, U.; Li, L.H.; Zhou, X.N.; Ok, U.Z.; Leelayoova, S.; et al. Oh my aching gut: Irritable bowel syndrome, Blastocystis, and asymptomatic infection. Parasit. Vectors 2008, 1, 40, doi: 10.1186/1756-3305$1-40$. 
124. Utzinger, J.; Zhou, X.N.; Chen, M.G.; Bergquist, R. Conquering schistosomiasis in China: The long march. Acta Trop. 2005, 96, 69-96.

125. Zhou, X.N.; Bergquist, R.; Leonardo, L.; Yang, G.J.; Yang, K.; Sudomo, M.; Olveda, R. Schistosomiasis japonica: Control and research needs. Adv. Parasitol. 2010, 72, 145-178.

126. Collins, C.; Xu, J.; Tang, S. Schistosomiasis control and the health system in China. Inf. Dis. Poverty 2012, 1, 7, doi: 10.1186/2049-9957-1-8.

127. Wang, L.D.; Guo, J.G.; Wu, X.H.; Chen, H.G.; Wang, T.P.; Zhu, S.P.; Zhang, Z.H.; Steinmann, P.; Yang, G.J.; Wang, S.P.; et al. China's new strategy to block Schistosoma japonicum transmission: Experiences and impact beyond schistosomiasis. Trop. Med. Int. Health 2009, 14, 1475-1483.

128. Wu, X.H.; Wang, L.P.; Li, S.Z.; Wang, X.H.; Tao, H.Q.; Pan, H.D.; Li, Y.S.; Li, X.M.; Huang, S.Y.; Zhou, X.N. The process and strategy in elimination of Schistosomiasis in Guangdong, Shanghai, Fujian, Guangxi, Zhejiang Provinces. In The Course and Perspectives in Schistosomiasis Control in China; Wang, L.D., Ed.; People's Health Press: Beijing, China, 2006; p. 401.

129. Zhou, X.N.; Guo, J.G.; Wu, X.H.; Jiang, Q.W.; Zheng, J.; Dang, H.; Wang, X.H.; Xu, J.; Zhu, H.Q.; Wu, G.L.; et al. Epidemiology of schistosomiasis in the People's Republic of China, 2004. Emerg. Infect. Dis. 2007, 13, 1470-1476.

130. Hao, Y.; Zheng, H.; Zhu, R.; Guo, J.G.; Wu, X.H.; Wang, L.Y.; Chen, Z.; Zhou, X.N. Schistosomiasis situation in People's Republic of China in 2008. Chin. J. Schistosomiasis. Control. 2009, 21, 451-456.

131. Wang, L.; Utzinger, J.; Zhou, X.N. Schistosomiasis control: Experiences and lessons from China. Lancet 2008, 372, 1793-1795.

132. Wang, L.D.; Chen, H.G.; Guo, J.G.; Zeng, X.J.; Hong, X.L.; Xiong, J.J.; Wu, X.H.; Wang, X.H.; Wang, L.Y.; Xia, G.; et al. A strategy to control transmission of Schistosoma japonicum in China. N Engl. J. Med. 2009, 360, 121-128.

133. Murray, C.J. Quantifying the burden of disease: The technical basis for disability-adjusted life years. Bull. World Health Organ. 1994, 72, 429-445.

134. King, C.H.; Dickman, K.; Tisch, D.J. Reassessment of the cost of chronic helmintic infection: A meta-analysis of disability-related outcomes in endemic schistosomiasis. Lancet 2005, 365, 1561-1569.

135. Jia, T.W.; Zhou, X.N.; Wang, X.H.; Utzinger, J.; Steinmann, P.; Wu, X.H. Assessment of the age-specific disability weight of chronic Schistosomiasis japonica. Bull. World Health Organ. 2007, 85, 458-465.

136. Mott, K.E. Schistosomiasis. In The Global Epidemiology of Infectious Diseases; Murray, C.J.L., Lopez, A.D., Mathers, C.D., Eds.; World Health Organization; Geneva, Switzerland, 2004; pp. 349-391.

137. Zhou, X.N.; Yang, G.J.; Yang, K.; Wang, X.H.; Hong, Q.B.; Sun, L.P.; Malone, J.B.; Kristensen, T.K.; Bergquist, N.R.; Utzinger, J. Potential impact of climate change on Schistosomiasis transmission in China. Am. J. Trop. Med. Hyg. 2008, 78, 188-194. 
138. Huang, Y.X.; Ren, Z.Y.; Hang, D.R.; Hong, Q.B.; Gao, Y.; Guo, J.H.; Sun, D.K.; Zuo, Y.P. Potential effect of climate changes on Schistosomiasis japonica transmission in east route of South-to-North Water Diversion Project. Chin. J. Schistosomiasis. Control. 2009, 21, 197-204.

139. Yang, G.J.; Utzinger, J.; Sun, L.P.; Hong, Q.B.; Vounatsou, P.; Tanner, M.; Zhou, X.N. Effect of temperature on the development of Schistosoma japonicum within Oncomelania hupensis, and hibernation of O. hupensis. Parasitol. Res. 2007, 100, 695-700.

140. Yang, G.J.; Utzinger, J.; Lv, S.; Qian, Y.J.; Li, S.Z.; Wang, Q.; Bergquist, R.; Vounatsou, P.; Li, W.; Yang, K.; et al. Regional network for Asian schistosomiasis and other helminth zoonoses (RNAS+): Target diseases in face of climate change. Adv. Parasitol. 2010, 72, 101-135.

141. Hu, W.; Yan, Q.; Shen, D.K.; Liu, F.; Zhu, Z.D.; Song, H.D.; Xu, X.R.; Wang, Z.J.; Rong, Y.P.; Zeng, L.C.; et al. Evolutionary and biomedical implications of a Schistosoma japonicum complementary DNA resource. Nat. Genet. 2003, 35, 139-147.

142. Consortium TSjGSaFA. The Schistosoma japonicum genome reveals features of host-parasite interplay. Nature 2009, 460, 345-351.

143. Liu, F.; Lu, J.; Hu, W.; Wang, S.Y.; Cui, S.J.; Chi, M.; Yan, Q.; Wang, X.R.; Song, H.D.; $\mathrm{Xu}, \mathrm{X} . \mathrm{N}$.; et al. New perspectives on host-parasite interplay by comparative transcriptomic and proteomic analyses of Schistosoma japonicum. PLoS Pathog. 2006, 2, e29, doi: 10.1371/ journal.ppat.0020029.

144. Wang, S.P.; Chen, X.C.; Gao, D.M. Research progress on Schistosome vaccine and prospect of its application in China. Chin. J. Parasitol. Parasit. Dis. 2009, 27, 402-411.

145. Xiao, S.H.; Keiser, J.; Chen, M.G.; Tanner, M.; Utzinger, J. Research and development of antischistosomal drugs in People's Republic of China: A 60-year review. Adv. Parasitol. 2010, 72, 231-295.

146. Xu, J.; Feng, T.; Guo, J.G.; Zheng, H.; Wang, Q.; Wu, X.H.; Zhou, X.N. Comprehensive evaluation of several diagnosis agents of schistosomiasis japonica in China. Chin. J. Schistosomiasis. Control. 2005, 17, 116-119.

147. Li, S.Z.; Wang, Y.X.; Yang, K.; Liu, Q.; Wang, Q.; Zhang, Y.; Wu, X.H.; Guo, J.G.; Bergquist, R.; Zhou, X.N. Landscape genetics: The correlation of spatial and genetic distances of Oncomelania hupensis, the intermediate host snail of Schistosoma japonicum in mainland China. Geospat. Health 2009, 3, 221-231.

148. Zhao, Q.P.; Jiang, M.S.; Littlewood, D.T.; Nie, P. Distinct genetic diversity of Oncomelania hupensis, intermediate host of Schistosoma japonicum in mainland China as revealed by ITS sequences. PLoS Negl. Trop. Dis. 2010, 4, e611, doi: 10.1371/journal. pntd.0000611.

149. Graczyk, T.K.; Fried, B. Development of Fasciola Hepatica in the Intermediate Host; CABI Publishing: Oxon, UK, 1999.

150. Mas-coma, S.; Valero, M.A.; Bargues, M.D. Fasciola, Lymnaeids and human fascioliasis, with a global overview on disease transmission, epidemiology, evolutionary genetics, molecular epidemiology and control. Adv. Parasitol. 2009, 69, 41-146.

151. Fica, A.; Dabanch, J.; Farias, C.; Castro, M.; Jercic, M.I.; Weitzel, T. Acute fascioliasisClinical and epidemiological features of four patients in Chile. Clin. Microbiol. Infect. 2011, 18, 91-96. 
152. Marsden, P.D. Fascioliasis in man: An outbreak in Hampshire. Br. Med. J. 1960, 2, 619-625.

153. Aksoy, D.Y.; Kerimoglu, U.; Oto, A.; Erguven, S.; Arslan, S.; Unal, S.; Batman, F.; Bayraktar, Y. Fasciola hepatica infection: Clinical and computerized tomographic findings of ten patients. Turk. J. Gastroenterol. 2006, 17, 40-45.

154. Bjorland, J.; Bryan, R.T.; Strauss, W.; Hillyer, G.V.; McAuley, J.B. An outbreak of acute fascioliasis among Aymara Indians in the Bolivian Altiplano. Clin. Infect. Dis. 1995, 21, $1228-1233$.

155. Xuan, T.; Hung, N.T.; Waikagul, J. Cutaneous fascioliasis: A case report in Vietnam. Am. J. Trop. Med. Hyg. 2005, 72, 508-509.

156. Flores, M.; Merino-Angulo, J.; Aguirre Errasti, C. Pulmonary infiltrates as first sign of infection by Fasciola. hepatica. Eur. J. Respir. Dis. 1982, 63, 231-233.

157. Chen, M.G. Fasciola. hepatica infection in China. Southeast Asian J. Trop. Med. Public Health 1991, 22, 356-360.

158. Lin, R.Q.; Dong, S.J.; Nie, K.; Wang, C.R.; Song, H.Q.; Li, A.X.; Huang, W.Y.; Zhu, X.Q. Sequence analysis of the first internal transcribed spacer of rDNA supports the existence of the intermediate Fasciola between $F$. hepatica and F. gigantica in mainland China. Parasitol. Res. 2007, 101, 813-817.

159. Lin, R.Q.; Dong, S.J.; Xu, C.X.; Huang, W.Y.; Song, H.Q.; Zhu, X.Q. DNA polymorphism in first internal transcribed spacer (ITS-1) rDNA of Fasciola. from Mainland China. Chin. J. Vet. Sci. Technol. 2004, 34, 8-12.

160. Huang, W.Y.; Dong, S.J.; Yang, X.Y.; Lin, R.Q.; Qian, D.X.; Zhang, W.Y.; Song, H.Q.; Zhu, X.Q. DNA polymorphism of the mitochondrial NADH dehydrogenase subunit 1 gene (nad1) of Fasciola. from China. Chin. J. Prev. Vet. Med. 2005, 27, 273-276.

161. Keiser, J.; Engels, D.; Buscher, G.; Utzinger, J. Triclabendazole for the treatment of fascioliasis and paragonimiasis. Expert Opin. Investig. Drugs 2005, 14, 1513-1526.

162. Huang, W.Y.; He, B. Chinese Fasciola. detemination by ITS2 sequence and RFLP. Anim. Sci. Vet. Med. 2002, 19, 2-6.

163. Dong, S.J.; Huang, W.Y.; Lin, R.Q.; Qian, D.X.; Wu, S.Q.; Song, H.D.; Zhu, X.Q. DNA polymophism of the mitochondrial cytochrome c oxidase subunit 1 gene (cox 1 ) of Fasciola. from Mainland China. Chin. J. Vet. Sci. 2005, 25, 378-381.

164. Weng, Y.L.; Zuang, Z.L.; Lu, C.X.; Yao, T.L. Drinking water is a new transmission route of Fasciolopsis buski for human and animals. Chin. J. Zool. 1980, 23, 48-50.

165. Lin, Y.G.; Cai, J.Z.; Weng, Y.L.; Zhang, C.X.; Yan, R.L.; He, Y.C.; Zheng, Y.Z.; Chen, Q.Q.; Chen, M. Studies on the epidemiology and treatment of human fasciolopsiasis in Putian district, Fujian province. J. Xiamen Univ. 1978, 17, 118-129.

166. Xiong, J.J.; Deng, Z.B. Epidemiology of intestinal parasitic diseases in 61,392 residents in Jiangling county. Chin. J. Rural Med. 1994, 22, 14-15.

167. Xu, Y.C.; Xu, F. Severe anemia and oedema due to Fasciolopsis buski infection. J. Clin. Transfusion Lab. Med. 2009, 11, 274.

168. Wang, K.X.; Wang, H.Y.; He, Q.; Ye, S. Case report: Intestinal obstruction due to Fasciolopsis buski infection. Chin. J. Surg. 2005, 43, 1168. 
169. Zhou, R.G. Case report: Fasciolopsis buski infection in biliary tract. Chin. J. General Surg. 2003, $12,493$.

170. Chen, X.L.; Yuan, Y.; Chen, Q.; Zhou, Y.S.; Zhang, X.H.; Liu, H. Studies on detecting antibodies in human sera of Fasciolopsiasis buski by ELISA. J. Centr. Chin. Norm. Univ. 2004, $38,85-87$.

171. Zhang, Y.; Yang, Z.N.; Jiang, N.; Hu, H.B. 13 cases of patients with fasciolopsiasis diagnosed by gastroscopy at early stage of infection. Zhejiang J. Clin. Med. 2002, 4, 356.

172. Bouvard, V.; Baan, R.; Straif, K.; Grosse, Y.; Secretan, B.; El Ghissassi, F.; Benbrahim-Tallaa, L.; Guha, N.; Freeman, C.; Galichet, L. A review of human carcinogens-Part B: Biological agents. Lancet Oncol. 2009, 10, 321-322.

173. Qian, M.-B.; Chen, Y.-D.; Yan, F. Time to tackle clonorchiasis in China. Infect. Dis. Poverty 2013, 2, 1-5. doi: 10.1186/2049-9957-2-4.

174. Furst, T.; Keiser, J.; Utzinger, J. Global burden of human food-borne trematodiasis: A systematic review and meta-analysis. Lancet Infect. Dis. 2011, 12, 210-221.

175. Qian, M.B.; Chen, Y.D.; Liang, S.; Yang, G.J.; Zhou, X.N. The global epidemiology of clonorchiasis and its relation with cholangiocarcinoma. Infect. Dis. Poverty 2012, 1, 4, doi: 10.1186/ 2049-9957-1-4.

176. Yang, L.C.; Huang, B.Y.; Xue, G.F.; Li, X.L.; Mo, D.L. Relationship between infection of Clonorchis sinensis and hepatobiliary and pancreatic diseases. Chin. J. Hepatobiliary. Surg. 2004, 10, 165-166.

177. Qu, H.M.; Qu, Z.M.; Liang, J.L.; Jia, B. Case report: 4096 patients with clonorchiasis. J. Pathogen. Biol. 2006, 1, 197.

178. Hotez, P.J.; Ehrenberg, J.P. Escalating the global fight against neglected tropical diseases through interventions in the Asia Pacific region. Adv. Parasitol. 2010, 72, 31-53.

179. Parkin, D.M. The global health burden of infection-associated cancers in the year 2002. Int. J. Cancer 2006, 118, 3030-3044.

180. Wang, X.; Chen, W.; Huang, Y.; Sun, J.; Men, J.; Liu, H.; Luo, F.; Guo, L.; Lv, X.; Deng, C.; et al. The draft genome of the carcinogenic human liver fluke Clonorchis sinensis. Genome Biol. 2011, 12, R107, doi: 10.1186/gb-2011-12-10-r107.

181. Qian, M.B.; Chen, Y.D.; Fang, Y.Y.; Xu, L.Q.; Zhu, T.J.; Tan, T.; Zhou, C.H.; Wang, G.F.; Jia, T.W.; Yang, G.J.; Zhou, X.N. Disability weight of Clonorchis sinensis infection: Captured from community study and model simulation. PLoS Negl. Trop. Dis. 2011, 5, e1377, doi: 10.1371/journal.pntd.0001377.

182. Choi, M.H.; Park, S.K.; Li, Z.; Ji, Z.; Yu, G.; Feng, Z.; Xu, L.; Cho, S.Y.; Rim, H.J.; Lee, S.H.; Hong, S.T. Effect of control strategies on prevalence, incidence and re-infection of clonorchiasis in endemic areas of China. PLoS Negl. Trop. Dis. 2010, 4, e601, doi: 10.1371/journal. pntd.0000601.

183. Xiao, S.H.; Xue, J.; Wu, Z.X. Experimental study progress on tribendimidine, artemether and artesuante against Clonorchis sinensis and other trematodes. Chin. J. Parasitol. Parasit. Dis. 2009, 27, 65-69. 
184. Qian, M.B.; Yap, P.; Yang, Y.C.; Liang, H.; Jiang, Z.H.; Li, W.; Tan, Y.G.; Zhou, H.; Utzinger, J.; Zhou, X.N.; Keiser, J. Efficacy and safety of tribendimidine against Clonorchis sinensis. Clin. Infect. Dis. 2013, 56, e76-e82, doi: 10.1093/cid/cis1011.

185. Lv, S.; Zhang, Y.; Steinmann, P.; Zhou, X.N.; Utzinger, J. Helminth infections of the central nervous system occurring in Southeast Asia and the Far East. Adv. Parasitol. 2010, 73, 351-408.

186. Li, D.J.; Liao, Y.F.; Zhu, X.R.; Liu, S.X. Electroencephalogram analysis of 106 cases with cerebral paragonimiasis. J. Wenzhou Med. Coll. 1996, 26, 22-24.

187. Zhang, E.X. Clinical analysis of 38 pediatric cases with cerebral paragonimiasis in the west mountainous area of Hubei province. Clin. Pediatr. J. 1990, 8, 177-179.

188. Li, P.; Fu, P.; He, J.C. Analysis of the clinical type and therapeutic efficiency of 280 children cases with paragonimiasis. J. Pathogen Biol. 2008, 3, 2-3.

189. Wang, B.K.; Wang, H.X. Cerebral hemorrhage due to Paragonimus infection in Sichuan Province. J. Stroke Neurol. Dis. 1990, 7, 137-138.

190. Cui, J.; Wang, Z.Q.; Wu, F.; Jin, X.X. An outbreak of paragonimiosis in Zhengzhou city, China. Acta Trop. 1998, 70, 211-216.

191. Ruan, W.; Lin, C.P.; Yao, L.N.; Lai, J.; Xia, R.S.; Yao, S.R. An outbreak of paragonimiasis. Dis. Surveill. 2009, 24, 978-979.

192. Wang, C.Q.; Yang, S.J.; Pan, H.M.; Wang, D.J. Study on Paragonimus infection by drinking water. Chin. Prev. Med. 2008, 9, 675-676.

193. Huang, W.D.; Zhong, H.L. Successful infection of Paragonimus in dogs and cats by ingesting cercariae. Chin. J. Vet. Med. 2008, 44, 62-63.

194. Cheng, Y.Z.; Wu, X.P.; Li, L.S.; Lin, C.X.; Jiang, D.W. A new species of Tricula as the first intermetiate host of Paragonimus skriabini (Mesogastropoda: Pomatiopsidae) from China. Mar. Sci. 2009, 33, 97-99.

195. Cheng, Y.Z.; Li, L.S.; Lin, C.X.; Li, Y.S.; Fang, Y.Y.; Jiang, H.D.; Huang, C.Y.; Zhou, A.P.; Zhang, X. Two new species of Huananpotamonas the second intermediate host of Paragonimus skriabini (Decapoda: Potamidae). Chin. J. Zoonoses 2008, 24, 885-889.

196. Li, Y.S.; Cheng, Y.Z.; Lin, C.X.; Zhang, Z.P.; Zhou, X.M.; Jiang, M. A new species of freshwater crab infected with metacercariae of Paragonimus: The genus Huananpotamon tangi sp. nov. Chin. J. Zoonoses. 2008, 24, 125-127.

197. Cheng, Y.Z.; Lin, G.H.; Li, Y.S. Two new species of freshwater crabs (Decapoda: Potamidae) serving as intermediate hosts of Paragonimus in Fujian, China. Chin. J. Parasitol. Parasit. Dis. 2010, 26, 241-245.

198. Dan, X.Y.; Lin, C.X.; Li, Y.S.; Hu, Y.; Sheng, X.S.; Lou, H.Q. A new species of Paragonimus sheni-With a key to the species adult worm and metaceycariae of the genus Paragonimus in China. Chin. J. Zoonoses 2009, 25, 1143-1148.

199. Liu, C.Q.; Guan, F.; Chen, Y.; Niu, A.O. Preliminary analysis of genetic variation of 11 populations of Paragonimus in China by random amplified polymorphic DNA technique. Chin. J. Zoonoses 2008, 24, 1041-1044.

200. Qian, B.Z.; Sugiyama, H.; Zhu, Z.H. Studied on genetic variation of Paragonimus westermani in Ninghai, Zhejiang province. Chin. J. Trop. Dis. Parasitol. 2007, 6, 69-72. 
201. Yang, G.J.; Vounatsou, P.; Zhou, X.N.; Tanner, M.; Utzinger, J. A potential impact of climate change and water resource development on the transmission of Schistosoma japonicum in China. Parassitologia 2005, 47, 127-134.

202. McManus, D.P.; Gray, D.J.; Li, Y.; Feng, Z.; Williams, G.M.; Stewart, D.; Rey-Ladino, J.; Ross, A.G. Schistosomiasis in the People's Republic of China: The era of the Three Gorges Dam. Clin. Microbiol. Rev. 2010, 23, 442-466.

203. Li, Y.S.; Raso, G.; Zhao, Z.Y.; He, Y.K.; Ellis, M.K.; McManus, D.P. Large water management projects and schistosomiasis control, Dongting Lake region, China. Emerg. Infect. Dis. 2007, 13, 973-979.

204. Sun, J.G.; Li, J.M.; An, J.A.; Hu, Y.H.; Zhang, G.; Sun, X.H.; Sun, F.Y.; Bai, X.T.; Niu, W.Y.; Li, L. Functions of biogas construction on public health in rural areas. Chin. J. Health Educ. 2006, 22, 822-825.

205. Jiang, W.S.; Chen, H.G.; Zeng, X.J.; Hong, X.L.; Ge, J.; Hu, S.Z.; Li, J. Effectiveness analysis of harmless treatment of human faeces to control eggs contamination of soil-transmitted nematodes. J. Pathogen Biol. 2008, 3, 49-52.

206. Waltner-Toews, D. An ecosystem approach to health and its applications to tropical and emerging diseases. Cad. Saude Publica 2001, 17, 7-36.

207. Bergquist, R.; Whittaker, M. Strengthening control of neglected tropical diseases in the Asia Pacific region: Implications for health information priorities. Inf. Dis. Poverty 2012, 1, 4, doi: 10.1186/2049-9957-1-3.

208. Zhou, X.N.; Bergquist, R.; Tanner, M. Elimination of tropical disease through surveillance and response. Inf. Dis. Poverty 2013, 2, 1, doi: 10.1186/2049-9957-2-1.

(C) 2013 by the authors; licensee MDPI, Basel, Switzerland. This article is an open access article distributed under the terms and conditions of the Creative Commons Attribution license (http://creativecommons.org/licenses/by/3.0/). 